\title{
LA MORISCOLOGÍA EN REVISTAS ANDALUZAS (1962-1994)*
}

\author{
Angel Luis Cortés Peña**
}

El auge alcanzado por la bibliografía sobre estudios moriscos en las últimas décadas ha sido de tal envergadura ${ }^{1}$ que, para cualquier investigador, encierra no poca dificultad estar informado del enorme volumen de trabajos que aparecen de forma cotidiana no ya en los tradicionales y conocidos focos editoriales, sino en los lugares más insospechados, cuyo poder de difusión en muchas ocasiones es bien escaso. Por lo que respecta a la historiografía española ${ }^{2}$, todo ello ha determinado que, dentro del período al que me voy a referir, pronto surgieran trabajos que desde diferentes perspectivas han analizado la labor llevada a cabo en esta parcela historiográfica.

En más de una ocasión, este tipo de análisis -no me refiero, por tanto, a la simple inclusión, dentro de obras generales sobre moriscos, de repertorios

* Una primera redacción de este trabajo, que comprendía sólo hasta el año 1992, fue publicada en el tomo I de los Mélanges Louis Cardaillac, Zaghouan, 1995. Las numerosas erratas y la inexplicable mutilación allí sufrida -fue omitida la relación final de los artículos- han motivado que salga de nuevo a la luz, ampliando ahora el ámbito cronológico hasta 1994 e inorporando alguna ausencia anterior.

* Universidad de Granada.

1. Esta riquísima proliferación de libros, artículos, ponencias y comunicaciones a congresos ha tenido su origen en distintos factores entre los que hay que indicar la renovación que afectó a la historiografía española a partir de la década de los sesenta, una de cuyas nuevas vertientes se inclinó decisivamente hacia el estudio de los marginados, así como, también, el camino abierto por algunas obras, hoy ya clásicas, que, sin duda, han influido en el quehacer de los historiadores en los decenios más cercanos; en este sentido, las investigaciones de Caro Baroja, Lapeyre, Regla, Ladero Quesada, Cardaillac, Domínguez Ortiz, Vincent, García-Arenal..., entre otros, fueron paulatinamente sembrando una simiente que ha fructificado en abundantísima cosecha. Factor también a no desdeñar es el nuevo interés que, por variados motivos, se ha despertado en las últimas décadas por la historia local.

2. En el ámbito de la historiografía francesa habría que señalar al respecto -tras la antorcha encendida por F. Braudel- el ya lejano trabajo de R. ARIE («Les études sur les morisques en Espagne a la lumière de les travaux récents», en Revue des Etudes Islamiques, 1967, pp. 225229), seguido por el entusiasmo despertado en sus discípulos por Louis Cardaillac y Bernard Vincent, lo que ha originado la realización de distintos trabajos y tesis centrados en el análisis de la investigación sobre moriscos; quizás sea justo señalar como último importante hito de este interés fuera de España el VI Symposium International d'Etudes Morisques, organizado por el CEROMDI en Zaghouan (Túnez) en septiembre de 1993, dedicado al Etat des Etudes de Moriscologie durant les trente dernières années. 
bibliográficos más o menos amplios ${ }^{3}$ - se ha incorporado, en la introducción o en algún capítulo específico, a trabajos más amplios de investigación o de síntesis ${ }^{4}$, o, también, ha aparecido como una parte de los «estudios preliminares» de algunas nuevas ediciones de estudios pioneros ${ }^{5}$. No obstante, de modo autónomo, parece de estricta justicia destacar en este campo los artículos de García Cárcel, García-Arenal y Márquez Villanueva, así como el libro de Miguel Angel de Bunes ${ }^{6}$; en ellos se pueden encontrar esclarecedores comentarios sobre los principales avances historiográficos realizados hasta el momento de su respectiva redacción y, lo que es más importante, se marcan los puntos de debate que nos permiten adentrarnos en, $\mathrm{o}$, al menos, vislumbrar, futuros caminos de investigación.

Esta es, estimo, una de las funciones primordiales -quizás la principalde los trabajos de tipo historiográfico; otra es la de dar a conocer a un público amplio la producción efectuada por los investigadores, que, a veces, desafortunadamente no encuentra los cauces adecuados para su difusión. Mi in-

3. En este sentido cabe indicar la, en su momento, importante síntesis bibliográfica aparecida en la obra de DOMínguez OrTiz, A. y Vincent, B. (Historia de los moriscos. Vida y tragedia de una minoría, Madrid, Revista de Occidente, 1979). A nivel de repertorio hay que destacar, más recientemente, los realizados por P. FERNÁNDEZ en Cuadernos de la Biblioteca Islámica "Félix María Pareja", 18 (1988) y 19 (1989), y los contenidos en la revista de la Universidad de Oviedo Aljamía. Boletín de información bibliográfica.

4. Pueden servir de ejemplo, por citar dos casos alejados en el tiempo, las obras de J. REGLÁ (Estudios sobre moriscos, Valencia, Universidad, 1964) o de M. DE EPALZA (Los moriscos antes y después de la expulsión, Madrid, Mapfre, 1992).

5. Dos ejemplos pueden resaltarse, el de Rafael BEnÍteZ SÁNCHEZ-Blanco a la obra de Lea (LEA, Henry Charles, Los moriscos españoles. Su conversión y expulsión, Alicante, Inst. "Juan Gil-Albert", 1990) y el de Ricardo GARCÍA CÁRCEL a la edición facsímil de Boronat (BORONAT Y BARRACHINA, Pascual, Los moriscos españoles y su expulsión, Granada, Universidad, 1992, 2 vols.).

6. GARCíA CÁRCEL, Ricardo, «La historiografía sobre los moriscos españoles. Aproximación a un estado de la cuestión», en Estudis, 6, 1977, pp. 71-99. GARCíA-ArENAL, Mercedes, «Ultimos estudios sobre moriscos: estado de la cuestión», en Al-Qantara, IV, 1983, pp. 101114. Id., «El problema morisco: propuestas de discusión», en Al-Qantara, XIII, 1992, pp. 491 503. MÁrQUEZ VILlaNUEva, Francisco, «El problema historiográfico de los moriscos», en Bulletin Hispanique, 86, 1984, pp. 61-135. Se ha incluido en su vol. misceláneo El problema morisco (desde otras laderas), Madrid, Ed. Libertarias, 1991, pp. 98-195. BunEs, Miguel Angel de, Los moriscos en el pensamiento histórico. Historiografía de un grupo marginado, Madrid, Cátedra, 1983.

Asimismo, aunque referido sólo al ámbito granadino y a la temática de la repoblación, me parece obligado incluir aquí el espléndido estudio bibliográfico de Rafael G. PEINADO SANTAELLA sobre la primera fase de la repoblación granadina, lo que, por otra parte me ahorrará reiterar algunos comentarios, «La repoblación del reino de Granada. Estado de la cuestión y perspectivas de investigación», en Actas del Coloquio de la V Asamblea General de la Sociedad Española de Estudios medievales, Zaragoza, 1991, pp. 273-334. También, la conferencia pronunciada por Manuel BarRIOS AGUILERA en septiembre de 1991 en el IV Curso Superior de Lengua y Cultura Española (Para Profesores Marroquíes y Españoles en Marruecos), «Una aproximación biblio-historiográfica a los moriscos granadinos». Ha sido editada en su volumen misceláneo Moriscos y repoblación en las postrimerías de la Granada islámica, Granada, Diputación Provincial, 1993, pp. 23-41. 
tención a la hora de escribir estas páginas se encuentra más en esta línea, con el intento de ser lo más exhaustivo posible a la hora de relacionar los artículos aparecidos en los últimos treinta años en publicaciones periódicas editadas en tierras andaluzas ${ }^{7}$.

Soy consciente de que mi empeño ha podido no cubrir en su totalidad el objetivo propuesto, ya que en estas décadas no han dejado de surgir boletines, anuarios o revistas, auspiciados por numerosas entidades públicas $\mathrm{y} / \mathrm{o}$ privadas, cuyo completo conocimiento resulta de gran dificultad incluso para quienes vivimos y trabajamos en la misma Andalucía; en todo caso, pienso que las posibles ausencias serán mínimas y de no excesiva importancia, aunque en algún caso muy concreto pudiera resultar una falta lamentable ${ }^{8}$.

Quisiera señalar, por último, en estos párrafos introductorios, dos aspectos a tener en cuenta. El primero, que, a pesar de la utilización del término morisco en el mismo título de estas páginas, he incluido lógicamente la etapa mudéjar del reino granadino (1492-1501), origen directo de la posterior conflictividad entre cristianos viejos y moris $\cos ^{9}$. El segundo se refiere a un límite temático: salvo específicas excepciones, justificadas por incidir de un modo especial en lo morisco o por su muy reciente edición, he dejado de relacionar la mayoría de los artículos sobre la repoblación posterior a 1570; cierto que al estudiar la acción de los repobladores cristianos viejos aparecen a cada instante conexiones con el período morisco, pero su inclusión hubiese acrecentado en exceso nuestro objetivo de forma totalmente innecesaria y reiterativa, dados los excelentes trabajos bibliográficos existentes al respecto ${ }^{10}$.

7. He recogido la producción de revistas, anuarios o boletines, a las que he añadido las comunicaciones presentadas en los Congresos anuales celebrados por la Asociación de Profesores de Geografía e Historia de Bachillerato "Hespérides", debido a que su continuada e ininterrumpida edición obliga, en cierto modo, a considerar su publicación como un anuario.

8. En determinados casos, algunas publicaciones no han sido tenidas en cuenta debido a la clara misión divulgativa de sus páginas, sin que sus artículos, demasiado sintéticos en general, hayan supuesto aportación alguna como labor investigadora. Ejemplo de ello es la revista Wadi-as, editada en la localidad granadina de Guadix, que ha dedicado, en algunos de sus números, un cuadernillo central a difundir la historia de localidades de su comarca. Sin duda es una labor meritoria y plausible, pero, dado su carácter de divulgación, por otro lado necesaria, he preferido no incluirla.

9. Fuera de las aportaciones aparecidas en las revistas, es ineludible indicar para este período el importante trabajo de Angel GaLÁN SÁNCHEZ, Los mudéjares del Reino de Granada, Granada, Universidad, 1991, cuya publicación no sólo ha supuesto la realización de una necesaria síntesis que recogiera los últimos avances historiográficos, sino que ha llenado algunos de los vacíos existentes y, a la vez, ha establecido nuevas bases sobre las que profundizar en el nacimiento de la cuestión morisca.

10. Si hace ocho años, Manuel Barrios Aguilera y Margarita M. Birriel Salcedo trataron de modo exhaustivo el tema en un minucioso libro, La repoblación del Reino de Granada después de la expulsión de los moriscos, Granada, Universidad/Grupo de Autores Unidos, 1986, con posterioridad el profesor Barrios, ya en solitario, ha seguido insistiendo sobre la cuestión. Primero fue en su "Estudio preliminar" a la edición facsímil de la obra de Francisco OrIOL. 
Una simple mirada a la relación de artículos publicados en los últimos treinta años en las revistas andaluzas ofrecen una primera constatación, me refiero al hecho de que en una altísima proporción se ocupan de los moriscos del reino de Granada, algo que tiene su explicación en el espacio geográfico en el que de modo fundamental se ubican los investigadores que han participado en las mismas"11; por otro lado, esta masiva presencia de "lo granadino" ha venido a subsanar desequilibrios preexistentes con anterioridad, ya que los estudios sobre moriscos abarcaban una gama de aspectos más variada en otras regiones.

Los trabajos no dedicados de modo expreso al reino de Granada pueden agruparse en dos bloques diferenciados: por un lado, aquellos que se ocupan de una temática general; por otro, los que atienden a moriscos asentados en otras comarcas.

El primer bloque lo preside un artículo de Domínguez Ortiz, quien, en el mismo 1962, sintetizó los aspectos más sobresalientes sobre demografía, distribución espacial, estructura social, religiosidad, ..., -la mayoría de cuyas apreciaciones no han sufrido corrección por la investigación posterior-, para concluir con un rechazo de opiniones sesgadas mantenidas por un cierta historiografía tradicional sobre la expulsión; sus palabras no pudieron ser más elocuentes:

“... puede afirmarse que la expulsión de los moriscos no fue el producto de un anhelo popular, sino una decisión tomada por un corto número de dirigentes movidos unos de un indiscreto celo religioso y otros por razones de alta política"12.

CATENA, La repoblación del Reino de Granada después de la expulsión de los moriscos, Granada, Universidad, 1987; después, con un tono más crítico y combativo, ha realizado un «Balance y perspectivas de la investigación acerca de la repoblación del Reino de Granada después de la expulsión de los moriscos», en Almería entre culturas. Siglos XIII al XVI, Almería, Instituto de Estudios Almerienses, 1990, II, pp. 613-665 (recopilado asimismo en el vol. misceláneo ya citado Moriscos y repoblación..., pp. 43-90). Finalmente, como "drástico epítome", en palabras del autor, ha escrito «La repoblación del reino de Granada por Felipe III, en $L a$ incorporación de Granada a la Corona de Castilla. Actas del Symposium conmemorativo del Quinto Centenario, (Granada, 2 al 5 de diciembre de 1991), Edición a cargo de Miguel Angel LADERO QUESADA, Granada, Diputación Provincial, 1993, pp. 607-628.

11. De las 28 publicaciones relacionadas, 18 son editadas en provincias situadas dentro del espacio del antiguo reino granadino -4 en Almería, 11 en Granada y 3 en Málaga-, 8 en el resto de Andalucía -3 en Cádiz, 2 en Córdoba, 2 en Sevilla y 1 en Jaén-, 1, por desgracia extinguida, cuya capitalidad editorial comparte Granada con Madrid, y una última cuya edición ha oscilado entre distintas capitales andaluzas. Si el número resulta claramente mayoritario para aquellas publicaciones que tienen -o tenían- su sede en el antiguo solar nazarí, aún es más abrumador en cuanto a los artículos en ellas aparecidos, de los 225 trabajos aquí recogidos, 194 pertenecen a revistas del ámbito granadino (puede verse de forma pormenorizada en la relación de revistas incluidas al final del artículo).

12. Domfnguez Ortiz, A., «Notas para una sociología...», p. 54. Hemos preferido indicar de este modo los distintos artículos del trabajo, remitiendo al lector interesado a la relación situada al final, donde se hallan incluidos todos los datos de la correspondiente edición. 
Años más tarde -en 1978-, Bernard Vincent iba a profundizar en un aspecto concreto apuntado en el artículo anterior, la familia, incidiendo no sólo en su peculiar estructura, con sus diferencias con el modelo de los cristianos viejos, sino en la presión asimiladora sufrida por el grupo familiar; a la espera de otras investigaciones, en opinión del autor, y a pesar del fracaso en lo esencial de la política de asimilación,

"el tiempo, los inevitables intercambios entre las dos comunidades y la repetición de medidas aculturantes habían atenuado seriamente los caracteres específicos de la familia morisca" ${ }^{\prime 13}$.

A propósito de la asimilación, Benítez Sánchez-Blanco defiende que

"al no ser reconocidos como iguales a los cristianos viejos, a pesar de la conversión, carecieron del estímulo del posible interés para asumir las pautas culturales de éstos como vía para la integración y el ascenso social"14.

En el mismo artículo, el profesor Benítez trata de la «protección» recibida por los moriscos por parte de la elite cristiano vieja -en particular los señores, sin olvidar al monarca- a cambio de una detracción de sus rentas. Asimismo nos anuncia en sus páginas un próximo trabajo en el que tratará de demostrar una hipótesis en cuanto al motivo fundamental de la expulsión; adelanta que se trató fundamentalmente de una simple operación de imagen con la finalidad de contrarrestar el «fracaso» que, para ciertos sectores, había supuesto la firma de la Tregua de los Doce Años.

Particular importancia tienen el conjunto de artículos referidos al enfrentamiento religioso, contemplado desde diferentes perspectivas. Así, los escritos por L. P. Harvey, quien desde sus conocimientos lingüísticos nos da noticias de textos escritos utilizados por los moriscos en este campo ${ }^{15}$, y el de Angel C. López sobre un Alcorán mudéjar o morisco, conservado en Granada ${ }^{16}$; o el artículo publicado por Louis Cardaillac sobre el paralelismo entre moriscos y protestantes, contemplados como una doble amenaza para su fe y su Monarquía por los españoles del siglo XVI y primeros años del $\mathrm{XVII}^{17}$. Más recientemente el mismo Cardaillac nos ha ofrecido una clarificadora síntesis del conflicto abierto entre las dos comunidades, indicando de modo especial los problemas relativos a las diferencias culturales y religiosas y resaltando como

13. VINCENT, B., «La famille morisque...», p. 28 (cito por la versión española).

14. BeníteZ SÁNCHEZ-BLANCO, R., «Control político y explotación económica...», p. 26.

15. HARVEY, L.P., «A morisco manuscript...» y «A morisco prayer-book...».

16. López, Angel C., «El Alcorán morisco de...».

17. CARDaillac, L., «Morisques et Protestants...». Paso con rapidez sobre tan interesante artículo dada su amplia difusión al incluirse, años más tarde, como capítulo III de su Moriscos y cristianos. Un enfrentamiento polémico (1492-1640), Madrid, F.C.E., 1979 (primera edición en francés, 1977). 
"el herético perseguido por la Inquisición no sólo comete una impertinencia hacia Dios sino que, en una sociedad cuyo cimiento es la fe cristiana, amenaza la cohesión social. La herejía es una verdadera subversión social"18.

Agudas observaciones nos ofrece Mercedes García-Arenal en su estudio comparativo de la evangelización de los moriscos y la de los amerindios; sus palabras sugieren reflexiones y plantean problemas que incitan al debate y a la investigación. No duda en ver una manifestación similar en la literatura aljamiado-morisca y los cronistas indígenas americanos; en los dos casos se muestra

"el mismo deseo de preservar el conocimiento de la cultura autóctona unida a la amargura por la destrucción de los exponentes de la misma, y en particular los libros, usando a veces expresiones sorprendentemente idénticas para expresar sus sentimientos. Ambas recurren a la elaboración o más bien al sincretismo religioso ${ }^{\prime 19}$.

Uno de los textos donde más claramente se plasmó este espíritu sincretista, a veces presente entre los moriscos, fue el denominado «Evangelio de Barnabé», sobre cuyo autor, sin embargo, a juicio de Epalza, aun nos encontramos en tinieblas ${ }^{20}$.

No sólo han sido los textos de tipo religioso los que han recibido la atención de los investigadores, así Harvey, además de ocuparse de la investigación puramente lingüística ${ }^{21}$, nos ha expuesto el hecho, aparentemente curioso, de cómo un escrito de un morisco sobre los turcos pudo tener como fuente una obra redactada en francés ${ }^{22}$. En esta relación de los moriscos con los turcos, un artículo revelador, por lo que respecta a las esperanzas que los primeros habían depositado en una posible ayuda de los segundos, es el de Monroe sobre una qasida, escrita, según el autor, por un morisco en 1501 y dirigida al sultán otomano solicitando su intercesión ante las autoridades cristianas ${ }^{23}$; pienso que, dadas las precisiones que posteriormente se han realizado sobre ese momento, sería oportuno volver a profundizar en el análisis de tan interesantes versos.

En cuanto a los moriscos asentados en otras regiones de la Península fuera del reino de Granada, existe una gran variedad de estudios no sólo espacial, sino también, cronológica y temática. No faltan trabajos que se ocupan de los últimos momentos del período mudéjar castellano, como el de Wagner sobre un grupo de mudéjares sevillanos ${ }^{24}$, o el dedicado por García-

18. CARDAILlaC, L., «El enfrentamiento entre...», p. 33.

19. Garcia-ARENAl, M., «Moriscos e Indios...», p. 174.

20. EPAlZA, M. de, «Sobre un posible autor...».

21. HARVEY, L.P., «The arabic dialect...».

22. HARVEY, L.P., «A morisco reader of Jean...».

23. MONROE, James T., «A curious morisco appeal...».

24. WAGNER, K., «Un padrón desconocido...». 
Arenal a la aljama de Uclés en 1501, cuyos habitantes no dudaron en dar el «salto» de la conversión meses antes del decreto que la hacía forzosa -salvo la alternativa del exilio-, donde pueden leerse frases tan enjundiosas como ésta:

"Siglos de convivencia cristiana y de fuertes presiones sociales y económicas debían haber erosionado notablemente el islamismo de los mudéjares castellanos. Quizás la conversión supusiera al principio un alivio, pero no cabe duda de que la condición del morisco llegó a ser más baja y más dura aún que la del mudéjar" 25 .

Fue la obligada conversión, unida, por supuesto, a otras medidas represoras, la que motivaría un cuarto de siglo más tarde la revuelta de la sierra de Espadán, objeto de un ejemplar estudio por parte del profesor García Cárcel, en el que no olvida insistir tanto en los factores que condicionaron el paulatino endurecimiento de la postura de la Corona, como en la creciente animadversión que se había producido hacia los mudéjares valencianos, lo que, sin duda, también influyó en la actitud del monarca:

"Las razones de la agresividad popular son una compleja acumulación de sentimientos en los que se entremezclan racistas animosidades, histerismos religiosos y una obsesión clasista producida por la competencia insalvable que el mudéjar implicaba para el campesino cristiano en el limitado mercado de trabajo por su condición de servil «esquirol» del señor feudal" 26 .

Referente a este ámbito valenciano existe, dentro de las revistas que consideramos, un importante trabajo de Juan Bautista Vilar sobre los moriscos de Orihuela; en él se ofrece un panorama de toda la problemática sobre la cuestión a lo largo del siglo XVI, analizándose las tensas relaciones entre cristianos viejos y moriscos, la distribución geográfica de estos últimos, sus relaciones con los granadinos, el papel de la nobleza, el problema religioso,..., para terminar con la misma expulsión ${ }^{27}$.

Finalmente, también dentro del mundo de los moriscos valencianos están los estudios de A. Labarta y C. Barceló sobre temas médicos, en los que sus autoras defienden, al contrario de lo comunmente sostenido, que los médicos moriscos no se diferenciaban de sus colegas cristianos ni en conocimientos teóricos ni en la práctica ${ }^{28}$.

Aunque referidos a moriscos avecindados fuera de Granada, existe una serie de trabajos que, sin embargo, se hallan en plena relación con el antiguo reino nazarí, ya que, en muy alta proporción, el asentamiento de los mismos

25. GARCíA-ARENAL, M., «Dos documentos sobre...», p. 177.

26. GARCIA CÁRCEL, R., «La revuelta morisca de...», pp. 121-122.

27. VILAR, J.B., «Los moriscos de la gobernación...».

28. LABARTA, A., «Textos para el estudio de terapéutica...». LABARTA, A. y BARCEló, C., «Nuevas recetas médicas...». 
tiene su origen en la expulsión del territorio granadino en 1570-71. En primer lugar, por su continuada presencia, hay que destacar los artículos del profesor Juan Aranda, quien no sólo nos ha proporcionado valiosas aportaciones sobre la presencia de esta minoría en las tierras cordobesas, sin olvidar la especificidad de las comarcas señoriales ${ }^{29}$, sino que, además, nos ha revelado preciosas noticias sobre grupos asentados en Sevilla y aspectos importantes referentes a la situación económica de los instalados en el reino de Jaén ${ }^{30}$; a todo lo cual hay que añadir la atención que le ha merecido la celosa actividad inquisitorial del tribunal cordobés del Santo Oficio, originada por las nuevas comunidades moriscas surgidas en su territorio después de $1570^{31}$. En este mismo sentido, aunque centrado en un aspecto más concreto se halla el trabajo de Ruiz Vera sobre la represión inquisitorial en amplias comarcas del valle del Guadalquivir ${ }^{32}$.

Dentro de este mismo tipo de trabajos hay que encuadrar el realizado por Angel Luis Molina, quien, tras las huellas del buen estudio global de Chacón Jiménez, analiza a los moriscos avecindados en Murcia en 1573 procedentes del valle del Almanzora y concluye admitiendo cómo, a pesar de no producirse la integración social,

"la receptividad de la sociedad murciana no es desfavorable para el morisco, ya que juega un papel indispensable en la economía local -la mayoría de ellos [...] desarrolla una actividad relacionada con las labores agrícolas y de la sedapor eso se les defiende y ampara a nivel oficial cuando llega la orden de que se eche fuera «a los moriscos que estuvieren en este reyno dentro de las doze leguas de los reynos de Granada y de Aragón y Valencia, los que fueren de sesenta abaxo y de quinze años arriba ${ }^{\prime \prime 33}$.

En cuanto a los moriscos del reino de Jaén, tres aportaciones más nos ofrecen José Carlos de Torres, Pedro A. Porras y Rafael Galiano. El primero se ocupa del tema morisco al tratar la marginalidad en una localidad concreta -Andújar- siguiendo textos literarios del Siglo de $\mathrm{Oro}^{34}$; el segundo nos proporciona una abundante relación de documentos -no exclusivamente jiennenses--, referidos a moriscos, existentes en los archivos de los condes de Bornos y Humanes y el de protocolos de Jaén ${ }^{35}$; y el tercero ha hecho un interesante estudio sobre la comunidad morisca asentada en las villas de Cambil

29. ARANDa DONCEL, J., "Contribución al estudio de...», «Potencial económico de la población...» $\mathrm{y}$ «Trayectoria demográfica...».

30. ARANDA DONCEL, J., «Estructura de la población morisca...» y «Los bienes inmuebles...».

31. ARANDA DONCEL, I., «La Inquisición de Córdoba...».

32. RUIZ VERA, J.L., «El mundo rural ante...».

33. MOLINA Molina, A.L., "Moriscos murcianos procedentes...», p. 75.

34. TORRES, J.C. de, «Brujas, pícaros y celestinas...».

35. PorRas ARboledas, Pedro A., «Documentos sobre musulmanes...». 
y Alhabar, algunos de cuyos miembros llegaron a alcanzar una desahogada situación económica ${ }^{36}$.

Podemos agrupar en otro bloque aquellos artículos que tratan, desde muy diferentes perspectivas, la conexión con el Norte de Africa. Así, dando paso a un variado calidoscopio, podemos comenzar la relación por los del $\mathrm{P}$. Cabanelas sobre las relaciones diplomáticas de Felipe II con los sultanes marroquíes ${ }^{37}$, o los que Gozalbes Busto dedica al estudio del exilio granadino en Marruecos, con particular incidencia en el caso de Tetuán ${ }^{38}$. Este último autor $^{39}$, así como el P. Tapia Garrido ${ }^{40}$, también han abordado los problemas del cautiverio en tierras maghrebíes, mientras que Carlos Gozalbes ha escrito sobre tema tan sugestivo como es el de la contrabando de armas a Marruecos ${ }^{41}$. El profesor Epalza ha sido otro de los investigadores que se han ocupado con insistencia del asentamiento morisco en las distintas comarcas norteafricanas, con la virtud añadida de ofrecernos en su día nuevas fuentes historiográficas al respecto -archivos del consulado de Francia en Túnez- ${ }^{42}$.

En cuanto a los aspectos mercantiles tenemos el riguroso trabajo de José Enrique López de Coca, tan ilustrativo de la mentalidad que se tenía a comienzos de la época moderna sobre el comercio y la guerra, con la particularidad en esta ocasión de tratarse de relaciones mercantiles con los infieles; de ahí el indiscutible protagonismo que alcanza la figura del Pontífice ${ }^{43}$.

En relación de algún modo con el Norte de Africa, pueden citarse los artículos que se ocupan del sistema de defensa costera en la costa del reino de Granada ante el temor de los ataques berberiscos y, también, con la misión de vigilar las huidas clandestinas de los moriscos a allende, ejemplo de las mismas tenemos en el artículo de José Luis Puga sobre los moriscos de Orgiva ${ }^{44}$. Dejando al margen aquellos que sólo se ocupan de aspectos puramente técnicos o no establecen relación alguna con la población morisca, tenemos en primer lugar el trabajo de López de Coca, quien definitivamente rechazó la tesis sostenida por Rachel Arié sobre la existencia de una conti-

36. GaLIANO PUY, R., «Historia de los moriscos procedentes...».

37. CABAnELAS, D., «Diego Marín, agente de Felipe II...» y «Pedro Venegas de Córdoba...».

38. GOZAlBES BUSTO, G., «Huellas vejeriegas...», «Notas sobre la tradición...», «La sociedad granadina-nasrí...», «Personajes moriscos...» y «La nobleza granadina». La dedicación del autor al tema ha tenido como fruto publicaciones de mayor amplitud entre las que cabe destacarse Los Moriscos en Marruecos. Granada, 1992.

39. Gozalbes Busto, G., «Cautiverios y redenciones...».

40. TAPIA Garrido, J.A., «El cura de Albox...».

41. Gozalbes CRAvioto, C., «Andalucía y el contrabando...».

42. EPAlza, M. de, «Moriscos y andalusíes...».

43. LÓPEZ DE COCA CASTAÑER, I.E., «Relaciones mercantiles...».

44. Puga Barroso, J.L., «Moriscos de la Tahá...». 
nuidad en el sistema financiero de la defensa costera y, siguiendo los pasos de Gámir y Ladero Quesada, rechaza el origen nazarí del nuevo sistema y precisa el nacimiento del mismo:

"El nuevo impuesto fue concebido como una capitación que se demandaba sin atender el valor de la hacienda de cada tributario, estando obligados a satisfacerla todos los varones musulmanes en edad de hacer açala, es decir, mayores de 16 años. Esta última circunstancia permite afirmar que habían de pagar todos los mudéjares en edad de prestar servicio militar.

En principio el reparto de la nueva carga se limitó a los musulmanes residentes en poblaciones costeras, entendiéndose por éstos, en la práctica, todas aquellas localidades ubicadas al sur del paralelo de Granada, en las comarcas que engloban lo que Sermet denomina Andalucía mediterránea" ${ }^{45}$.

Esta línea de investigación es continuada por Ana $\mathrm{M}^{\mathrm{a}}$. Vera, quien nos da una visión bastante completa de la readaptación de la infraestructura defensiva de la costa malagueña tras la revuelta de 1500-1501, insistiendo en los problemas de financiación de la misma ${ }^{46}$. Con posterioridad, $\mathrm{N}$. Cabrillana, con su particular buenhacer, ha puesto de manifiesto cómo la iniciativa privada también tuvo su protagonismo en este terreno, dado el perjuicio soportado por muchos particulares ante las repetidas negligencias derivadas del mal funcionamiento del sistema real ${ }^{47}$, mal funcionamiento que no impedía una presión fiscal a veces determinante de otras situaciones gravosas para los vecinos de la zona, como muestra el trabajo de José Luis Barea $^{48}$. A consignar también una breve aportación documental sobre el impuesto de la farda realizada por $\mathrm{M}^{\mathrm{a}}$. Angustias Olmedo ${ }^{49}$, así como un trabajo de $\mathrm{M}^{\mathrm{a}}$. Luisa Campos que, aunque se ocupa de modo especial de la renta de población no deja de hacer importantes precisiones sobre la farda ${ }^{50}$. Finalmente, Gil Sanjuán también trata de la farda, aunque dentro de un estudio de mayor amplitud sobre la presión fiscal y las exacciones sufridas por la comunidad morisca, en el que aparte de las enajenaciones inquisitoriales y

45. López de COCA CASTAÑer, J.E., «Financiación mudéjar del...», p. 190. Aunque no publicado en una revista andaluza, es necesario consignar aquí un reciente artículo de sumo interés, dado que realiza una magnífica síntesis sobre el estado de la cuestión y, además, aporta nuevas e importantes precisiones sobre el asunto; es el de Javier CASTILLO FERNÁNDEZ, "Administración y recaudación de los impuestos para la defensa del reino de Granada: La farda de la mar y el servicio ordinario (1501-1516)», en Areas, 14, 1992, pp. 67-90.

46. VerA DelGado, A.M"., «La readaptación del sistema...».

47. Cabrillana, N., «La defensa costera del...».

48. BAREA FERRER, J.L., «La defensa de Motril...». El autor que ya se había ocupado del tema en su tesis doctoral ha hecho un magnífico estado de la cuestión en su estudio preliminar a la edición facsímil de la obra de A. GAMIR SANDOval, Organización de la defensa de la costa del Reino de Granada desde su Reconquista hasta finales del siglo XVI, Granada, Universidad, 1988.

49. Moreno Olmedo, $M^{a}$.A., «Contribución al estudio de...».

50. CAMPOS DAROCA, Ma.L., «Rentas particulares del...». 
las confiscaciones bélicas, se refiere a algunas de las prácticas cotidianas de represión económica; por ejemplo:

"Las dotaciones de los beneficiados en poblaciones moriscas eran mínimas, ya que obispos y capitulares se habían apropiado una parte del tanto por ciento que les correspondía en el reparto de la décima. Esto repercutió desfavorablemente en los cristianos nuevos los cuales se vieron sometidos a exacciones por parte del clero, exigiéndoles las primicias y elevando las taas arancelarias por los servicios religiosos ${ }^{251}$.

Quizás sea el momento de volver atrás cronológicamente y relacionar los numerosos trabajos que han dado nueva luz a aspectos muy variados de los últimos años del período mudéjar castellano; me refiero a la etapa que transcurrió entre la conquista del reino de Granada y la conversión forzosa, espacio breve, pero de suma importancia debido a la trascendencia que para el inmediato futuro iba a suponer el fracaso del establecimiento de una sociedad dual. El profesor Acién Almansa publicó sus reflexiones sobre dos textos mudéjares de la serranía de Ronda ${ }^{52}$ a través de las cuales no sólo confirma algunas precisiones lingüísticas sobre el árabe grandino, sino que revela hasta qué punto llegaba la suspicacia y control sobre la población vencida, desde un primer momento, $\mathrm{y}$, a la vez, nos suministra información muy válida sobre los modos de vida en la frontera. Después, unido a López de Coca, hicieron un planteamiento de la cuestión mudéjar en tierras malagueñas, resaltando:

"cómo a costa de los vencidos se teje muy pronto una red de intereses, donde se mezclan los de la Corona y los de los repobladores. Rivalizando con ellos encontramos los de los vecinos cristianos del otro lado de la antigua frontera y los de la nobleza beneficiaria de los señoríos jurisdiccionales en tierras malagueñas" ${ }^{\prime \prime 3}$.

Este artículo fijó unas líneas de trabajo, seguidas después activamente por un grupo de investigadores que han ido desvelando aspectos básicos de esta etapa. Un ejemplo, la aportación de Angel Galán sobre la propiedad mudéjar de la Axarquía malagueña ${ }^{54}$. Muy interesante asimismo el análisis de Vallvé Bermejo sobre el repartimiento de Comares ${ }^{55}$, de valor, además, tanto para el estudio de las instítuciones nazaríes, como para el de la toponimia y la fonética del árabe hispano.

51. GIL SANJUÁN, J., «Presión material sobre...», p. 187.

52. ACIÉN Almansa, M., «Dos textos mudéjares...».

53. ACiÉn Almansa, M. y López de COCA CASTAÑer, J.E., «La cuestión mudéjar...», p. 39.

54. GALÁN SÁNCHEZ, A., «Algunos rasgos de la propiedad...». Parece imprescindible citar aquí la obra fundamental de este autor sobre el período, Los mudéjares del reino de Granada. Granada, Universidad/Diputación Provincial, 1991.

55. VAllvê Bermejo, J., «Sobre el repartimiento de...». 
Sanz Sampelayo ha incidido asimismo en el conocimiento de estos años en los que, anacrónicamente, se intentó una convivencia abocada desde sus inicios al fracaso; a través de su estudio sobre los comienzos del cabildo granadino se percibe la imposibilidad de futuro de esta sociedad dual dibujada en las capitulaciones ${ }^{56}$. En este mismo esquema hay que situar el artículo de Juan Antonio Grima sobre las ordenanzas de la Alhambra de 1492, aunque en este caso se matiza la actuación de los Reyes Católicos en el sentido de que los mismos nunca estuvieron dispuestos a cumplir de verdad lo acordado en las capitulaciones ${ }^{57}$, postura defendida también por otros historiadores y que paulatinamente parece ser cada día más aceptada.

Cualquiera que fuese la intención de los Reyes Católicos, lo cierto es que el mayor conocimiento que se ha producido sobre el establecimiento de la población castellana tras la conquista, confirma, sin margen de dudas, que la coexistencia pacífica y tolerante entre vencedores y vencidos era una irrealizable quimera, motivada por diferentes factores surgidos en uno y otro bando, pero con especial presión de la actitud de rapiña de una parte considerable de los repobladores, como puede apreciarse en las consideraciones de José Szmolka sobre la reactivación de la economía granadina tras la conquista ${ }^{58}$. Muchos son los trabajos que se han realizado profundizando en esta temática; en nuestro objeto de atención -treinta últimos años de revistas andaluzas- existen abundantes muestras. Abarcando la generalidad del reino y enlazando fiscalidad y repoblación, el profesor López de Coca publicó en 1978 un interesante artículo con presupuestos de gran novedad -así, la importancia dada a la intervención de motivos fiscales en la convesión forzosa de los mudéjares- ${ }^{59}$, que, como ha sucedido con otros trabajos suyos, ha propiciado, como veremos, posteriores investigaciones al respecto.

El primitivo asentamiento castellano en las comarcas de la costa granadina ha originado una proliferación de estudios, en una gran mayoría realizados, dirigidos o auspiciados por Antonio Malpica, quien, a lo largo del tiempo, y desde la utilización del documento a la prospección arqueológica sobre el terreno, está originando el conocimiento de la implantación castellana y el consiguiente cambio estructural que la misma supuso ${ }^{60}$; junto con lo editado en revistas de fuera del ámbito andaluz y sus aportaciones en congresos, colo-

56. SANZ SAMPELAYO, J., "Configuración inicial e...».

57. GRIMA CERVANTES, J.A., «Gobierno y administración de...». De este mismo autor se ha publicado una interesante recopilación de trabajos, en la que se incluyen artículos aquí no relacionados debido a su primitivo lugar de aparición, Almería y el Reino de Granada en los inicios de la modernidad (s. XV-XVI), Almería, Arráez, 1993.

58. SZMOLKA Clares, J., «La reactivación de la economía...».

59. LÓPEZ DE COCA CASTAÑer, J.E., «Privilegios fiscales y...».

60. Malpica Cuello, A., "La villa de Motril y...», «Primeros elementos de análisis...», «La implantación castellana...» y «La costa de Granada...»; así como, en colaboración con J.A. RODRíGueZ LOZANO, «La alquería de Cázulas...». 
quios y homenajes, son numerosas publicaciones que ya reclaman de su autor el necesario trabajo de síntesis globalizadora del fenómeno ${ }^{61}$. En esta misma línea hay que colocar las investigaciones de Teresa Armada, Encarnación Escañuela y José Pérez García ${ }^{62}$. En una perspectiva distinta, y dedicada a una zona del interior, se halla la aportación de López Dapena, que nos informa de diferentes rentas cobradas en Guadix por la hacienda real, tanto a cristianos viejos como a mudéjares o moriscos, en los años 1494, 1501 y $1502^{63}$; asimismo, la de Espinar Moreno y otras colaboradoras sobre la agricultura de la alquería de Laroya a comienzos del siglo XVI ${ }^{64}$.

Por lo que respecta al ámbito espacial de la costa almeriense, esta primera etapa de la incorporación a Castilla está representada por un trabajo de Rodríguez Martínez, en el que analiza los problemas iniciales del proceso en la propia ciudad de Almería ${ }^{65}$, otro de García Guzmán sobre bienes habices en $1496^{66}$, y por tres artículos de Victoriano del Cerro sobre Vera y su tierra, en los que se clarifica la situación política y socioeconómica de los mudéjares de la zona, así como se da noticia de los pocos datos hasta ahora conocidos del repartimiento de Vera ${ }^{67}$.

Asimismo tenemos trabajos que se ocupan del territorio del obispado de Málaga durante los primeros lustros de la conquista. López de Coca tiene un estudio centrado en un aspecto muy concreto -el intento repoblador de Fuengirola-, ejemplo de lo sucedido en otros lugares costeros, donde la amenaza pirática y problemas derivados de la propiedad de la tierra llevaron al fracaso la proyectada repoblación ${ }^{68}$. Por las mismas fechas publica también un extenso e intenso artículo dedicado al análisis de la ocupación del territorio malagueño partiendo de la estrategia castellana de repoblación exclusiva de las ciudades y mantenimiento de los indígenas en los distritos rurales, con el común denominador de la explotación del vencido; el carácter militar de la repoblación, la presión fiscal sobre el mudéjar, las excesivas expropiaciones -en parte no deseadas por la Corona-,... son factores que se mezclan y conducen a

61. En parte ha cubierto esta necesidad la publicación de su volumen misceláneo La costa de Granada en la Edad Media. Poblamiento y territorio. Granada, Ayuntamiento de Motril, 1994.

62. Armada Morales, T. y Escañuela Cuenca, E., «La presencia castellana y...». Pérez García, J., «El poblamiento de la taha...».

63. López Dapena, A., "Las rentas de Guadix...».

64. Espinar Moreno, M., Alvarez del Castillo, Mª A. y Guerrero Lafuente, Ma.D., «La alquería de Laroya...».

65. RodRÍGUez MARTíneZ, F., «Aspectos socioeconómicos...».

66. GARCÍA GUZMÁN, Ma . del M., «Bienes habices del convento de...».

67. CERRO BEX, V. del, «Un padrón de los mudéjares...», «Vera y su "tierra"...» y «El repartimiento de...».

68. LOPEZ DE COCA CASTAÑER, J.E., «Fuengirola, un caso...». 
"que los ingresos fiscales no bastan para satisfacer las necesidades del nuevo orden político que los castellanos instalan en tierras de Málaga. No es una realidad privativa de ésta, sino general a todo el recién conquistado reino granadino, que durante algunos años seguirá costando dinero a la hacienda real, agobiada por los gastos que originan las necesidades militares y eclesiásticas ${ }^{\prime \prime 69}$.

Suberbiola, con un planteamiento marxista ingenuamente radical -presente en muchas investigaciones historiográficas de la década de los 70-, insiste en los problemas de la repoblación de Málaga derivados de la presión fiscal, haciendo especial hincapié en la importancia de las relaciones diplomáticas de los Reyes Católicos con Inocencio VIII encaminadas a conseguir las bulas pontificias necesarias que posibilitaran la obtención de las exacciones precisas para el control de las tierras conquistadas ${ }^{70}$.

Es conocido por todos cómo la continuada presión sobre los vencidos y el comienzo del incumplimiento de las capitulaciones fueron factores determinantes de la revuelta de fin de siglo, prólogo de la previsible medida conminatoria de la conversión de los mudéjares castellanos. La revuelta dio origen a una serie de episodios bélicos que, fuera de toda duda, serían considerados en algunos momentos como una nueva guerra de conquista, si no de todo el reino granadino, sí de algunas de sus comarcas; desde luego, así parecen demostrarlo las repercusiones sociales y económicas que se manifestaron en los vecinos reinos de Jaén y de Murcia, según analizan los trabajos de Rodríguez Molina, Argente del Castillo y los hermanos Abellán Pérez ${ }^{71}$.

La nueva situación creada con la revuelta iba a afectar a toda la población morisca, hubiese participado o no en la misma. Ya antes de producirse la definitiva pragmática en la que los Reyes Católicos determinan la conversión o el exilio -14 de febrero de 1502-, se iniciaron las conversiones masivas, auspiciadas por las prometidas medidas de perdón y por la fuerte preșión de las autoridades, proceso estudiado para el caso de Málaga por el profesor López de $\mathrm{Coca}^{72}$ y, a la vez, comenzaron a ser firmadas nuevas capitulaciones con presupuestos bien diferentes de las primeras, como indica Grima Cervantes para el caso de los Vélez ${ }^{73}$. Galán,

A partir de ese momento -pragmática de 1502-, como ha escrito Angel

"quedará expedito el camino para intentar la asimilación por todos los medios posibles, sin engorrosos problemas legales y prácticos, acerca de a quién afectaban los decretos y medidas que se dicten.

69. LÓPEz de COCA CASTAÑER, J.E., «Poblamiento y frontera...», p. 40.

70. SUbERBIOLA, J. «Fisco, franquicias y...».

71. Abellán Pérez, J. y J.M ${ }^{a}$, «Aportación de Murcia a...». Argente del Castillo Ocaña, C., «Ultimos episodios de cautiverio...». Rodriguez MOLINA, J., «Participación de Jaén en....».

72. López de COCA CASTAÑer, J.E., «La "conversión general" en el...».

73. Grima CERVANTES, J.A., «Las capitulaciones pactadas...». 
Desde ahora, y prácticamente hasta 1511, el silencio legal se cierne sobre los moriscos granadinos. Son estos años de un intenso esfuerzo en la evangelización. Reflejo de los resultados de esta campaña catequizadora y de otras circunstancias son las medidas de 1511-1513"74.

Este trabajo del profesor Galán no es propiamente un artículo de revista, sino que sus dimensiones -número monográfico de Jábega- hacen de él un verdadero libro del que se extraen valiosas e importantes conclusiones, por ejemplo, el cambio definitivo del "status teórico" de los moriscos se produjo tras las medidas adoptadas en 1511-1513, la existencia de una cierta movilidad social en los últimos años del mudejarismo y en los primeros de la conversión por parte de algunos colaboracionistas... El autor lleva sus consideraciones hasta la asamblea de la Capilla Real de Granada en 1526, momento en que, para él, el proceso teórico-político de los moriscos finaliza:

"De ahora en adelante sólo podrán optar por tres caminos para defender su identidad: La lucha sorda y cotidiana contra la represión, comprar la benevolencia de la Corona o la sublevación armada. Los dos primeros fueron muy usados a lo largo del siglo XVI, el último desencadenó la sublevación de las Alpujarras de 1568 y su expulsión del reino ${ }^{\prime 75}$.

Abundan también los estudios sobre los aspectos demográficos y sociales. Por lo que respecta a la demografía, unos presentan aportaciones muy localizadas en el espacio y en el tiempo, como la de Pereiro Barbero sobre la Axarquía ${ }^{76}$, o las más extensas, desde el punto de vista geográfico, de José Luis Barea, a propósito de una "visita" a la costa en 1567"7 , o de Bravo Caro sobre las poblaciones moriscas malagueñas durante la guerra del $68^{78}$; otros nos ofrecen un estudio más profundo, como el realizado por Mercedes García-Arenal ${ }^{79}$ a través de las actas parroquiales de Comares, que incluye un interesante análisis onomástico, o el de Alfonso Franco -comprendiendo tanto a los cristianos viejos como a la población morisca- sobre las villas almerienses de los Vélez ${ }^{80}$. Un caso atípico está representado por un artículo de Juan Andrés Luna ${ }^{81}$, que estudia la expansión de un barrio cristiano viejo de Granada -el de la Magdalena-, en el que la proximidad de la Vega origina

74. GALÁN SÁNCHEZ, A., «Los moriscos de Málaga...», p. 12.

75. Ibídem, p. 16. La tercera parte de este estudio -bases socioeconómicas- conoció poco después una edición aparte, actualizada, en la revista sevillana Historia. Instituciones. Documentos, «Notas para el estudio del...».

76. Pereiro Barbero, P., «Incidencia de la expulsión...».

77. Barea Ferrer, J.L., «La población de la costa...».

78. Bravo CARO, J.J., "Poblaciones moriscas de...».

79. GARCIA-ARENAL, M., "Las actas parroquiales de...».

80. Franco SILVA, A., «Datos demográficos y...».

81. Luna DÍAz, J.A., «La parroquia de Santa María...». 
que, en 1561, sobre un total de 559 vecinos, 44 sean moriscos, rompiendo, por tanto, con la exclusiva concentración albaicinera de los mismos.

La temática social está presente en un artículo de Gil Sanjuán sobre disidentes y marginados en la Serranía de Ronda, aunque sus páginas son fundamentalmente de divulgación, sin que se aporten novedades reseñables ${ }^{82}$.

El problema de la esclavitud -a pesar de seguir siendo uno de los campos que aún necesita más investigación- ha merecido también la atención de los investigadores. En 1976, Enrique del Pino, en el monográfico de Jábega sobre la esclavitud en Málaga desde la Antigüedad hasta la época contemporánea, dedica unas páginas a nuestro período demasiado sucintas ${ }^{83}$; Espinar Moreno y García Guzmán aportan datos sobre precios, destinos y rescates de los esclavos procedentes de Albox como consecuencia de la guerra de $1568^{84}$; Alcaina Fernández ofrece unas noticias sobre esclavitud morisca y berberisca en el siglo XVII en los casos concretos de Vélez-Blanco y María ${ }^{85}$; Carlos Asenjo analiza asimismo la situación de los esclavos musulmanes en Guadix, especialmente en el siglo XVI, aportando 25 apéndices documentales que recogen casos concretos sobre los mismos ${ }^{86}$. Novedad, en la que habrá que insistir, nos ofrece el trabajo de $\mathrm{M}^{\mathrm{a}}$ Isabel Jiménez sobre la encomienda infantil ${ }^{87}$. Ahora bien, en este campo, el artículo más completo continúa siendo el publicado por Nicolás Cabrillana en 1975 sobre la esclavitud morisca de Almería en el XVI, realizado sobre más de mil quinientas actas notariales, con las que demostró de forma incontestable cómo la guerra de 1568 supuso para muchos cristianos un verdadero "negocio". Muchos son los aspectos que podríamos destacar de este importantísimo trabajo, si no creyéramos que es suficientemente conocido; me siento obligado, sin embargo, a transcribir un párrafo, cuya presencia pienso que es oportuna ${ }^{88}$; es éste:

"Ambos sectores de la población, cristiano viejo y morisco, aparecen separados por un muro invisible, a pesar de los contactos cotidianos. En ambos sectores hay pobres y ricos, nobles y plebeyos. No están, pues, desunidos por razones económicas, políticas o sociales, sino por algo mucho más imperceptible, mucho más sutil y mucho más fuerte: por algo tan carismático como el prestigio. El prestigio consistía para la mentalidad del siglo XVI en ser «cristiano desde siempre» y no descender de judío ni moro; en una palabra, en ser «cristiano viejo». Esto, que aparece bien claro en los documentos notariales y

82. GIL SANJUÁN, J., «Disidentes y marginados de...».

83. PINO, E. del, «La esclavitud en Málaga...».

84. ESPinar Moreno, M. y GarCía GuZmán, Ma . del M., «Notas sobre la esclavitud...».

85. Alcaina Fernández, P., «Esclavitud en Vélez Blanco y...».

86. ASENJO SEDANO, C., «Trabajo, honra y esclavos...».

87. JMMÉNEZ JURADO, $\mathrm{M}^{\mathrm{a}}$.I., «La encomienda infantil: una modalidad...».

88. En cuanto a su aceptación o a su debate, que, en todo caso, creo que podría servir para perfilar determinados matices en cuanto a las clases dirigentes. 
que no es aceptado por todos los historiadores actuales, constituye el punto de partida para la comprensión del problema de la esclavitud morisca" ${ }^{\prime 89}$.

En una vertiente bien diferente, dentro de los aspectos sociales, hay que situar la aportación documental de Antonio Malpica y Carmen Trillo sobre los denominados Infantes de Granada, representantes destacados de una minoría morisca cuya trayectoria vital fue muy distinta de la sufrida por el grueso de su comunidad ${ }^{90}$. También, los trabajos de Espinar Moreno y Grima Cervantes sobre otros personajes de esta oligarquía morisca ${ }^{91}$, así como el del profesor Peinado sobre uno de los linajes de la aristocracia granadina ${ }^{92}$.

Podríamos incluir dentro de este bloque sobre sociedad unas curiosas páginas escritas por Tapia Garrido, en las que trata de demostrar (?) que los Abduladin, moriscos principales de los Vélez, eran descendientes del duque Teodomiro $^{93}$. ¡Increíble! $\mathrm{O}$ estamos ante una alucinación o ante el intento de "explicar" con un nuevo tipo de razonamiento la restauración del cristianismo tras la reconquista. Sin comentarios.

La visión de conjunto de la comunidad morisca, con sus rasgos diferenciadores, aparece en los como siempre agudos comentarios de Bernard Vincent a propósito de la visión transmitida por los viajeros extranjeros de la época ${ }^{94}$.

En lo referente a temas económicos el número de artículos es aún más considerable, respondiendo a un variado espectro de cuestiones, algunas de difícil encasillamiento por su amplia temática, así el de Enrique Soria sobre los bienes de la casa real nazarí en Gor ${ }^{95}$. No faltan los estudios sobre sectores productivos muy concretos, como es el caso de las salinas ${ }^{96}$, o los dedicados a puntualizar los oscuros problemas derivados de sus contribuciones impositivas, en sentido amplio del término ${ }^{97}$, o aquéllos que recogen un pa-

89. Cabrillana, N., «Esclavos moriscos en...», pp. 53-54. Poco después, dentro de un contexto más amplio, puso a disposición de los investigadores nuevos documentos al respecto, Documentos notariales referentes a los moriscos (1569-1571). Archivo Histórico Provincial de Almería, Granada, Universidad, 1978.

90. Malpica Cuello, A. y Trillo San Jose, C., «Los Infantes de Granada...».

91. Espinar Moreno, M., «Abulcaçen Aben Cohbe...». Espinar Moreno, M. y Grima Cervantes, J.A., «Un personaje almeriense en...».

92. Peinado Santaella, R.G., «Los Banu al-Qabvani...».

93. TAPIA GARRIDO, J.A., «El último Abduladin...».

94. VINCENT, B., «La vision du Royaume...».

95. SORIA MESA, E., «La venta de bienes de...».

96. Gual Camarena, M. y López de Coca Castañer, J.E., «La sal del reino de...». Malpica Cuello, A., «Las salinas de Motril...».

97. BIRRIEL SALCEDO, M.Ma ., «Notas sobre la hacienda...», «Nuevos datos sobre el...». LOPEZ

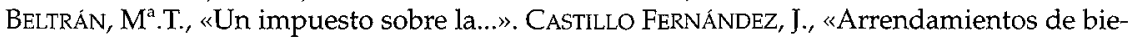
nes confiscados...». 
norama general de alguna de las infraestructuras básicas de la economía granadina, así el trabajo de Vincent, que se enfrenta con la situación del regadío antes y después de la expulsión de los moriscos del reino ${ }^{98}$, sosteniendo la tesis del fracaso de la repoblación debido, en alta proporción, a la inadaptación al sistema de irrigación por parte de los recién llegados. Recientemente, García Latorre ha mostrado su desacuerdo con este planteamiento para el caso almeriense:

"[...] no encuentro por ninguna parte referencias a problemas de adaptación técnica, sino un conflicto social que afecta al mantenimiento y la conservación del sistema hidráulico y de todo el espacio agrario del lugar. Los «feudales» habían visto descender vertiginosamente sus rentas a consecuencia de la expulsión. Hasta ese momento su exigencia de renta había podido compatibilizarse con la supervivencia de los sistemas agrarios moriscos, pero en la coyuntura desesperada que vivieron tras la salida de los moriscos intentaron una auténtica reacción señorial que, de prosperar, habría alterado completamente la organización de los espacios agrarios existente hasta ese momento y habría hecho fracasar la repoblación" ${ }^{\prime \prime 9}$.

Pienso que estamos ante la aparición de una muy interesante polémica que, si se profundiza, puede desvelarnos hechos básicos de la agricultura del reino de Granada en los siglos XVI y XVII.

Por lo que respecta al mundo rural del entorno de la capital granadina del quinientos, tras la relación de los cortijos de propiedad morisca hecha por Garzón Pareja ${ }^{100}$, existen cuatro importantes trabajos de Luna Díaz, que se ocupan tanto de aspectos productivos, como de propiedad y repoblación ${ }^{101}$.

La utilización de los libros de apeo para el conocimiento de la repoblación y de la continuidad o los cambios agrícolas de ella derivados, así como para realizar prospecciones sobre la agricultura de la etapa morisca ha sido frecuente por parte de muchos investigadores -como veremos más adelante, a veces demasiados-. En este sentido, en las revistas que contemplamos, existen trabajos de una variada gama de autores desde distintas perspectivas y con enfoques metodológicos muy diferentes, por tanto, también con resultados muy diversos, algunos francamente pobres ${ }^{102}$.

98. VINCENT, B., «Le réseau d'irrigation...».

99. GARCía LATORRE, J., «La pervivencia de los espacios...», pp. 305-306.

100. Garzón Pareja, M., "Cortijos del término de Granada...».

101. LunA Díaz, J.A., «Apuntes para el estudio...», «El Temple, "tierra" de...», «La alquería: Un modelo...» $\mathrm{y}$ "Repoblación y gran propiedad...».

102. Abellán Pérez, J., «Algunos aspectos socioeconómicos...». Barrios Aguilera, M., «Paisajes agrarios moriscos...». Id., "Ainadamar en el Archivo...». BIRRIEL SALCEDO, M.M"., «Propiedad y uso de la...» y "Ventas de bienes confiscados...». COTES PORCEL, J., «La repoblación de tierras...». MARTín Ruiz, F., «La economía del partido...». MARTín RuIz, J.Ma., "Distribución de los bienes...». Martínez López, J.M., Fuentes Arias, J. de la y Granados Moreno, P., 
Por su número, puden agruparse en un bloque los numerosos artículos que el profesor Espinar Moreno, bien en solitario o con distintos colaboradores, ha realizado sobre aspectos económicos y urbanísticos relacionados con los moriscos; unas veces utiliza los libros de apeo o de población ${ }^{103}$, otras, fuentes documentales diversas - protocolos, libros de repartimiento, fondos de la Chancillería, libros de habices...- ${ }^{104}$, quizás con una excesiva fragmentación a la hora de publicar los resultados de la investigación. También sobre el regadío hay que reseñar el trabajo de Sánchez Ramos ${ }^{105}$ sobre la Alpujarra y las tres entregas de bibliografía comentada que nos ha ofrecido Glick ${ }^{106}$, que sobrepasan el tiempo que aquí nos ocupa.

En la última década ha aparecido un nuevo objetivo en las preocupaciones de los investigadores, el problema de los moriscos de los lugares de señorío. Era lógico dada la importancia del tema y la escasez de conocimientos que poseiamos sobre el mismo. En la actualidad distintos trabajos doctorales en fase muy avanzada cubrirán el desfase existente en este campo con respecto a los datos conocidos de otras zonas. Mientras tanto han sido numerosos $-\mathrm{y}$, por ello, de distinto valor- los artículos publicados.

Sobre la cuenca del Almanzora, el prolífico Tapia Garrido ha escrito dos aportaciones aparecidas en la encomiable publicación sobre la comarca -al margen de la muy diferente calidad de sus colaboraciones- que es la revista Roel ${ }^{107}$, mientras que para esa misma zona encontramos aportaciones de interés en el trabajo de Alfonso Franco sobre el señoríos de los Vélez ${ }^{108}$. La zona malagueña está representada por el breve trabajo de Martín Ruiz sobre Bentomi $z^{109}$. Son distintas comarcas de la provincia granadina las que han sido objeto de una mayor atención investigadora; a los casos específicos de Gómez Lorente, con respecto a Gor ${ }^{110}$, y de Rafael Peinado, para Cam-

«Estudio de dos despoblados...». SANTIAGo Simón, E. de, «Algunos datos sobre...». TAPIA GARRIDO, J.A., «La agricultura en el...».

103. Espinar Moreno, M., "Apeo y deslinde de...», «Aspectos urbanos y rurales...», «Los árboles en las...» y «Notas sobre la historia de...». Espinar MOREno, M. y Alvarez del Castillo, Ma.A., «Análisis socioeconómico de...». Espinar Moreno, M. y Fernández Ortega, A., «Bienes rústicos de Cantoria...».

104. Espinar Moreno, M., «Aproximación al conocimiento...», «Bienes habices...», «Escenas de la vida...», «La alquería de Otura...», «Medidas de peso...», «Notas sobre la alquería...», «Notas sobre propiedades...», «Noticias para el estudio...» y «Reparto de las aguas...». Espinar Moreno, M. y QueSADA Gómez, J.J., «Estudios sobre la ciudad de...», «Las aguas de la acequia...». ESPINAR MORENO, M. y QUESADA GOMEZ, Mª.D., «El regadío en el distrito...». Espinar Moreno, M. y Quesada GomeZ, J.J. y M M $^{a}$.D., "Las aguas del río Nacimiento...».

105. SÁNCHEZ RAMOS, V., «Agua y regadío en la...».

106. GLICK, Thomas F., "Historia del regadío y...».

107. TAPTA CARr.IDO, J.A., «El señorío de los Fajardo...» $\mathrm{y}$ «Los señoríos del Almanzora...».

108. Franco Silva, A., «El señorío de los Vélez...».

109. MARTín Ruiz, J.M"., «Los lugares de señorío...».

110. GOMEZ LORENTE, M., «Los señoríos en el Reino...». 
potéjar $^{111}$, hay que añadir los que, desde distintos ángulos, han iluminado facetas hasta ahora desconocidas del atrayente marquesado del Cenete ${ }^{112}$. A la espera de mayores resultados, gracias a las investigaciones en curso, puede, no obstante, afirmarse que la importancia de los señoríos del reino de Granada en toda la "cuestión" morisca tuvo una mayor significación que la otorgada por la historiografía tradicional.

Puede formarse un bloque heterogéneo con todos aquellos artículos dedicados a estudios de léxico, antroponimia, cultura material... ${ }^{113}$, destacando en este conglomerado los dedicados a la toponimia, en los que de nuevo hay que señalar la diversidad de criterios y de profundidad de análisis existentes entre ellos ${ }^{114}$.

Si bien los aspectos religiosos se hallan presentes en un porcentaje elevado dentro de todo el conjunto de trabajos aquí reseñados, existe un número elevado que se ocupan del tema de un modo específico. Uno de los más destacados especialistas en esta faceta ha sido Jesús Suberbiola, quien, en un artículo en el que trata de manera particular el problema fiscal de tres partidos del obispado de Málaga, relaciona, una vez más, la política fiscal de la Monarquía con la conversión general mudéjar y la formación del Estado moderno ${ }^{115}$; las

111. Peinado Santael.LA, R.G., «Los orígenes del marquesado...».

112. ARIAs Abellán, J., «Los hombres y las tierras...». Espinar Moreno, M. y Ruiz PÉRez, R., «Datos para el estudio...». GÓMEZ LORENTE, M., «Aportaciones al estudio del...». RuIZ PÉREZ, R., «El magran, impuesto decisivo...».

113. Albarracín Navarro, J., «Juan Martínez Ruiz y el testamento...». Domínguez Bedmar, M., «Algunas posibles piezas...». MARTínez RUIZ, J., «Antroponimia morisca en...», "Hufra, hayar y sajar...», «La indumentaria de los...», «Recibos bilingües de pago...», «Visita a todas las casas...» y «Ausencia de literatura aljamiada...». Muñoz Martín, M ${ }^{2}$. del M. y Domínguez Bedmar, M., "Cerámica hispano-musulmana...». SANTIAGo Simón, E. de, «Algunos documentos arábigo-granadinos...». TORRES PALOMO, M . del M., «Sobre la carta de Ábenaboo...». VÁzQUEZ QUERO, A., "A propósito de la cultura...».

114. SeCo de LuCEna PAREdeS, L., «Toponimia árabe de la...». AbellÁN PÉREZ, J., «Voces hispanoárabes y...». CHAVARRÍA VARGAS, J.A., «De la fortaleza y sierra...». En realidad es un artículo de síntesis sobre Bentomiz, que dedica cierta extensión a la toponimia del lugar calificando de falsa la etimología sostenida hasta la fecha desde Mármol de Carvajal hasta Caro Baroja. Martínez Ruiz, J., «El Ár. 'Ard 'Tierra'...». Martínez Ruiz, J. y Barrios Aguilera, M., «Contribución a la toponimia ...». Díaz GARCía, A. y BarRIOS Agullera, M., "Nueva interpretación de...». Los autores, con criterios metodológicos nuevos, han insistido en el tema publicando De toponimia granadina. Un estudio histórico-lingilístico según el "Libro de Apeo y Repartimiento" de Alfacar, Granada, Universidad, 1991. En el mismo se dedica un capítulo completo a la bibliografía básica existente sobre la toponimia del reino de Granada.

115. Suberbiola, J., «Política físcal en la...». Expone una visión completa del problema en su Real Patronato de Granada. El arzobispo Talavera, la Iglesia y el Estado Moderno (1486-1516). Estudio y documentos, Granada, Caja General de Ahorros, 1985. Libro básico, aunque pienso que algunas de sus tesis necesitan una mayor demostración; de hecho, sus opiniones sobre los privilegios que la nueva situación eclesiástica suponían para la Monarquía, pronto fueron contestadas por A. RIESCO TERRERO, «Restauración de la sede de Málaga y de la vida parroquial y monástica en el Reino de Granada. Postura del papa Inocencio VIII y política de los Reyes Católicos», en Estudios sobre Málaga y el Reino de Granada en el V Centenario de su conquista, edit. por J.E. LOPEZ DE COCA CASTAÑER, Málaga, 1987. 
erecciones parroquiales de Granada y de Málaga, así como el reformismo cisneriano, en relación con la primera, y las cuestiones decimales del obispado de Málaga han sido objeto asimismo de su atención investigadora ${ }^{116}$; siguiendo su estela Jesús López estudió el caso de Almería ${ }^{117}$. Sobre esta primera etapa, en la que se pasa de lo musulmán a los cristiano en el reino granadino, existen cuatro aportaciones que dan noticias al respecto de lo sucedido en lugares concretos, Granada, Vélez Rubio, Baza y La Peza ${ }^{118}$. Garrido Aranda, antes de publicar su importante libro sobre la Iglesia granadina, ofreció un primer acercamiento al tema no excesivamente conseguido ${ }^{119}$.

Otros aspectos puntuales han sido asimismo tratados de un modo particular, así los problemas en torno a la Asamblea o Junta de 1526 en la Capilla Real granadina ${ }^{120}$, o las cuestiones relacionadas con la enseñanza a los moriscos ${ }^{121}$. Por último, fray Darío Cabanelas trató de desentrañar las oscuridades, relacionadas con el mundo morisco, que se habían tejido en torno a los libros plúmbeos del Sacromonte, aportando datos de gran valor $^{122}$.

Mención aparte merecen los muy numerosos artículos sobre los moriscos y el tribunal del Santo Oficio. El primero a consignar puede ser el trabajo de Pérez de Colosía y Gil Sanjuán sobre la actividad inquisitorial en Málaga durante la segunda mitad del siglo XVI, dada su considerable extensión -número monográfico de Jábega, cien páginas-y las fuentes utilizadas -relaciones de causas y correspondencia con la Suprema-, lo que les permite dibujar un panorama bastante completo sobre el camino seguido por la Inquisición antes y después de la sublevación morisca. Según los autores, quienes resaltan la función policial del tribunal,

"La evidente actividad represora por parte del Santo Oficio no admite otra explicación que la de una política deliberada para conseguir la asimilación total, a costa de la pérdida de identidad en los rasgos culturales de un pueblo sometido"123.

116. Suberbiola MARTinez, J., «Constituciones y rentas...», «La ordenación parroquial malacitana...» $\mathrm{y}$ «La erección parroquial granatense...».

117. LOPEZ ANDRÉs, J.M ${ }^{\mathrm{a}}$., «Real Patronato Eclesiástico...».

118. Núñez CONTRERAS, L., «La fecha de consagración...». TAPIA GARRIDO, J.A., «Primera iglesia y primeros...». ESPINAR MORENO, M., «Iglesias y ermitas de...». ESPINAR MORENO, M., QUESADA GOMEZ, J.J. y SÁEz MEDINA, J., «La villa de La Peza...».

119. Garrido ARANDA, A., "Papel de la Iglesia...». Su obra posterior, Organización de la Iglesia en el Reino de Granada y su proyección en Indias. Siglo XVI, Sevilla, Escuela de Ets. Hispanoamericanos, 1980 superó con creces este adelanto.

120. GiL SANJuÁN, J., «El parecer de Galíndez...».

121. López, M., «El colegio de los niños...». Álvarez Rodríguez, J.R., «La Casa de Doctrina...».

122. CABANELAS, D., «Cartas del morisco granadino...» y «Arias Montano y los libros...».

123. Pérez de Colosia Rodríguez, Maa.I. y Gil SANJUÁn, J., «Málaga y la Inquisición...», p. 24. 
Estos dos mismos historiadores, en alguna ocasión también en colaboración, pero casi siempre con aportaciones individualizadas, han publicado una serie de datos y noticias que ofrecen un abanico variado sobre el funcionamiento y actividad de la Inquisición granadina, en una gran parte encaminada a ejercer un control sobre los moriscos ${ }^{124}$.

También Bernard Vincent se ha ocupado de este apasionante tema, limitando en el tiempo su acercamiento a los años bélicos y los inmediatamente anteriores al estallido del conflicto; su análisis del trato dado por el tribunal a los distintos sectores sociales de la comunidad morisca se completa con la oportuna alusión a los "motivos espaciales":

"EI otro factor determinante de la represión inquisitorial contra los moriscos es el reparto de la población dentro del Reino. Está claro que los cristianos nuevos que viven en un medio mixto están más sujetos a persecuciones que los que se encuentran en un medio homogéneo [...] Los inquisidores apenas se aventuran a visitar sistemáticamente estas zonas en las que no se sienten seguros $^{\prime \prime 125}$.

Pelayo Alcaina y Lladó Granado han investigado sobre la actuación inquisitorial en distintas zonas de la actual provincia de Almería, incluida las tierras señoriales del marquesado de los Vélez, y sobre un curioso expediente a propósito de la probanza de limpieza de sangre de un aspirante a familiar del Santo Oficio ya en pleno siglo XVIII ${ }^{126}$.

Por lógicas razones cronológicas, he dejado para el final un último bloque de artículos referentes a la guerra de 1568 y a su trágico desenlace. En espera de tener una visión completa de la última guerra desencadenada por el Islam español con perspectivas metodológicas actuales, nos hemos de conformar con las aportaciones puntuales ofrecidas por distintos investigadores, a veces plasmadas en un cierto detallismo ${ }^{127}$. Si bien es verdad que algunos trabajos están exentos de novedad, ya que se limitan a exponer los hechos siguiendo las clásicas narraciones de Hurtado de Mendoza, Pérez de Hita y Mármol $^{128}$, en otros, aunque se ocupan esencialmente de narrar acontecimientos bélicos, se aportan algunos datos nuevos procedentes de fuentes do-

124. GL SANJUÁN, J., «La Inquisición de Granada...», «Moriscos, turcos y ...», «La otra cara de la...» y «Ofensiva final antimorisca...». PÉREZ DE COLOSIA RODRIGUEZ, M".I., «Visita inquisitorial de...», «Malagueños sentenciados por...» y «Represión inquisitorial después de la...». Pérez de Colosia Rodríguez, Ma.I. y Gil Sanjuán, J., "Los moriscos del Algarbe...».

125. VINCENT, B., «LOs moriscos y la Inquisición...», p. 200.

126. AlCAina Fernández, P., «La Inquisición en el...» y «Ascenso social y limpieza...». Lladó GRANADO, A.I. y AlCAINA FERNÁNDEZ, P., «Visita inquisitorial al obispado...».

127. Calero PaLACJOS, C., «Contribución al estudio...».

128. Navas ACOSTA, A., "La batalla de Frigiliana...». Perspectivas interesantes se ofrecen en CARRASCO URGOI'TI, Ma.S., «Experiencia y fabulación en...». 
cumentales diversas, por ejemplo, los de Pilar Núñez y de Tapia Garrido ${ }^{129}$, destacando en esta línea el muy documentado de Enrique Soria ${ }^{130}$. La actuación de los cabildos municipales de Jaén y de Málaga ante la sublevación han sido asimismo estudiados por López Ruiz y Bravo Caro ${ }^{131}$, y Ricardo Ruiz ha trazado un excelente panorama de lo que supuso la guerra en un territorio señorial, concretamente en el marquesado del Cenete ${ }^{132}$. No podía faltar la referencia a alguno de los religiosos asesinados durante la contienda; en este caso nos encontramos con un artículo de tipo apologético, alejado de una adecuada crítica histórica ${ }^{133}$.

En cuanto a la expulsión de los moriscos del reino de Granada son cinco los trabajos a reseñar. En primer lugar, uno, a pesar de su antigüedad, con plena validez, de Domínguez Ortiz, en el que, con su habitual maestría, ofrece una serie de datos sobre la suerte corrida por los granadinos entre su dispersión por tierras de la Corona de Castilla, fuera de Granada, y la expulsión definitiva en $1609^{134}$. Francisco Villegas realiza una muy aceptable síntesis de toda la problemática sobre la expulsión y unas interesantes reflexiones, en particular en cuanto a la demografía, sobre sus consecuencias ${ }^{135}$. Tapia Garrido muestra en este campo su preocupación por el pasado almeriense, narrando el desarrollo del proceso de expulsión de los moriscos del marquesado de los Vélez ${ }^{136}$. Por último, Antonio Muñoz toca uno de los aspectos más controvertidos a este respecto: los moriscos almerienses que consiguieron permanecer tras la expulsión ${ }^{137}$; trabajo al que de algún modo habría que añadir -aunque no sea ése su objetivo principal- el de Faustino Rodríguez ${ }^{138}$.

Termino, pues, este repaso, forzosamente breve, de la producción historiográfica sobre los moriscos, contenida en revistas del ámbito andaluz durante los últimos treinta años. Soy consciente de que, a pesar de la abundancia de artículos, no es completo el panorama de la investigación que sobre el tema morisco se ha llevado a cabo, no ya a niveles generales, sino incluso

129. Núnez Galiano, P., «La comarca de Bentomiz...». Sobre esta zona he citado artículos de diferentes autores, en la mayoría de los cuales se aprecia una evidente reiteración en la temática expuesta. TAPIA GARRIDO, J.A., «Rebelión de los moriscos...» y «Don Juan de Austria en...».

130. SORIA MESA, E., «Don Alonso de Granada Venegas y...».

131. López Ruiz, E., «La guerra contra los moriscos...». BRAvo CARO, J.J., «Medidas adoptadas por el...».

132. RUIZ PÉREZ, R., «El levantamiento morisco en...».

133. SÁEZ MEDINA, J., «El Santo Fray Marcos...».

134. DOMíNGUEZ ORTIZ, A., «Los moriscos granadinos antes...».

135. Viliegas MOLINA, F., «Algunas consideraciones sobre...».

136. TAPIA GARrido, J.A., «Expulsión de los moriscos...».

137. MuÑoz BuendíA, A., «Supervivencia de la población...».

138. Rodríguez MolinA, F., «Los conocedores moriscos...». 
dentro mismo de nuestra comunidad autónoma, donde han proliferado congresos, coloquios, simposios, jornadas, homenajes y otras conmemoraciones de muy diverso tipo, en muchos de los cuales se han presentado y publicado resultados de investigaciones de importancia. No obstante, creo que estas páginas son ilustrativas del trabajo que, de un modo más particular, se ha realizado en Andalucía, y, a la vez, pueden servir para que un público más amplio conozca una serie de autores y de revistas, quizás no divulgados de un modo conveniente, a los que, en más de un caso -y, lógicamente, no me refiero ahora a los historiadores conocidos- es necesario tener presente para profundizar en el conocimiento de esta esencial parcela de la historia española.

Cierto que no todo lo reseñado presenta una igual calidad. Aún más, y dejando al margen los artículos cuya fuerte carga ideológica los convierte en inservibles desde el punto de vista de la Historia, se percibe una cierta "ligereza" a la hora de publicar -quizás motivada por la necesidad de hacer con cierta rapidez un curriculum investigador-, que en ocasiones casi podría catalogarse como enfermiza. Esto da lugar, por un lado a que se investigue y se publique sin procurarse, previamente y/o de modo simultáneo, una apropiada formación historiográfica, lo que, a veces, queda patente en ignorancias bochornosas; por otro, al mal uso de una misma fuente, fragmentándola de forma increíble con el fin de posibilitar varias publicaciones -el caso de los libros de repartimiento y de apeo es clamoroso, como ha señalado García Latorre para algunos casos concretos que podrían ser ampliados ${ }^{139}-$, y, además, utilizando una arcaica metodología positivista como señalara en su día Mercedes García-Arenal ${ }^{140}$.

A pesar de todo ello, que no deja de ser grave, el avance realizado ha sido considerable, todavía más contemplando el trabajo llevado a cabo por todos los investigadores que se ocupan del tema, por lo que parece vislumbrarse la necesidad de una puesta al día de la síntesis sobre la historia de los moriscos realizada por Domínguez Ortiz y Bernard Vincent en 1979, en la que se incorporen las principales aportaciones de los últimos años.

Me siento obligado a finalizar con un cierto optimismo dado que algunos historiadores han comenzado a plantear nuevas hipótesis de trabajo con el intento de profundizar en el proceso de inserción/rechazo de la comunidad morisca -a niveles colectivos y/o individuales- dentro del conjunto de la sociedad española del siglo XVI. Es más que posible que estas nuevas líneas de investigación nos deparen en un cercano futuro alguna que otra grata sorpresa.

139. García LATORRE, J., «Arqueología medieval e historia moderna en el Reino de Granada. El caso de la sierra de Filabres", en CN, 20 (1992), p. 205.

140. GARCÍA-ARENAL, M., «Ultimos estudios sobre...», p. 107. 


\section{RELACIÓN DE REVISTAS ANDALUZAS CON BIBLIOGRAFÍA SOBRE MORISCOS, INDICANDO LAS SIGLAS CON LAS QUE SE CITAN}

Al-Andalus (Granada-Madrid). -16- $A A$

Almuñécar. Arqueología e historia (Almuñécar, Granada). -1- $A A H$

Anales de la Universidad de Cádiz (Cádiz). -1- AUC

Anales del Colegio Universitario de Almería (Almería). -1-ACUA

Anales del Instituto Nacional de Bachillerato «Luis de Góngora» (Córdoba). -1- AINB

Anuario de Historia Moderna y Contemporánea (Granada). -2-AHMC

Archivo Hispalense (Sevilla). -1- AH

Baetica (Málaga). -20-BT

Boletín de la Real Academia de Córdoba de Ciencias, Bellas Letras y Nobles Artes (Córdoba). -5- BRAC

Boletin del Instituto de Estudios Almerienses (Almería). -4-BIEA

Boletín del Instituto de Estudios Giennenses (Jaén). -3-BIEG

Boletín del Instituto de Estudios «Pedro Suárez» (Guadix, Granada). -3- BIEP

Chronica Nova (Granada). -29- CN

Congreso de Profesores-Investigadores de la Asociación de Profesores de Historia de Bachillerato de Andalucía «Hespérides». -6-C.P.I.

Cuadernos de Ciencias Económicas y Empresariales (Málaga). -1- CCEE

Cuadernos de Estudios Medievales. A partir del $\mathrm{n}^{\circ} 19$ recibe el nombre Cuadernos de Estudios Medievales y Ciencias y Técnicas Historiográficas (Granada). -20-CEM

Cuadernos de la Alhambra (Granada). -8- CA

Cuadernos Geográficos de la Universidad de Granada (Granada). -4-CGUG

Dynamis (Granada). -2-DY

Estudios de Historia y Arqueología Medievales (Cádiz). -6-EHAM

Foro de las Ciencias y de las Letras (Granada). -2- FCL

Gades (Cádiz). -1- GD

Historia. Instituciones. Documentos (Sevilla). -5- HID

Jábega (Málaga). -12-JB

Miscelánea de Estudios Arabes y Hebraicos (Granada). -21-MEAH

Revista del Centro de Estudios Históricos de Granada y su Reino (Granada). -15-RCHG

Revista Velezana (Vélez Rubio, Almería). -9-RV

Roel (Albox, Almería). -26-RL 


\section{RELACIÓN DE ARTÍCULOS SOBRE MUDÉJARES Y MORISCOS}

\section{DE LAS REVISTAS ANDALUZAS CITADAS, ENTRE 1962 × 1992}

ABELLÁN PÉREZ, Juan, «Algunos aspectos socioeconómicos de Albox a través de su libro de Apeo», RL, 1 (1980), pp. 43-47.

- «Voces hispano-árabes y mozárabes referentes a los accidentes de la naturaleza en la toponimia menor de Comares (Málaga)», EHAM, II (1982), pp. 51-59.

ABELlán PÉReZ, J. y J.Ma ${ }^{\mathrm{a}}$, «Aportación de Murcia a la rebelión morisca de la Alpujarra almeriense: el cerco de Velefique», CEM, IV-V (1976-1977), pp. 27-39.

ACIÉN AlmANSA, Manuel, «Dos textos mudéjares de la serranía de Ronda (1491)», CEM, II-III (1974-1975), pp. 245-257.

ACIÉN AlmaNSA, M. y LóPez de COCA CASTAÑer, J.E., «La cuestión mudéjar en tierras de Málaga»,JB, 12 (1975), pp. 36-43.

AlbarRacín NAVARRo, Joaquina, "Juan Martínez Ruiz y el testamento de María Xaylona», RCHG, 6 (1992), 2"época, pp. 277-295.

Alcaina FernándeZ, Pelayo, "Ascenso social y limpieza de sangre en el s. XVIII: la estirpe de los Gamboa de María», RV, 10 (1991), pp. 7-10.

— «Esclavitud en Vélez Blanco y María en el siglo XVII», RV, 9 (1990), pp. 13-20.

- «La Inquisición en el marquesado de los Vélez. La visita de 1561», RV, 7 (1988), pp. 24-32.

Alvarez Rodríguez, J. Rosaura, «La Casa de doctrina del Albaicín. Labor apostólica de la Compañía de Jesús con los moriscos», CA, 19-20 (1983-1984), pp. 233-246.

ARANDA DONCEL, Juan, «Contribución al estudio de los moriscos en Córdoba», AINB, III (1972), pp. 69-78.

- «Estructura de la población morisca en tres parroquias sevillanas, San Julián, San Román y Santa Lucía», BRAC, 96 (1976), pp. 77-84.

- «La Inquisición de Córdoba y la visita de distrito en el último tercio del siglo $X V I \gg, B R A C, 109$ (1985), pp. 5-40.

- «Los bienes inmuebles de los moriscos granadinos en el Reino de Jaén», BRAC, 101 (1980), pp. 109-125.

- «Potencial económico de la población morisca en Córdoba», BRAC, 92 (1972), pp. 127-152.

- «Trayectoria demográfica y estructura de la población morisca en el área señorial cordobesa (1569-1610)», BRAC, 105 (1983), pp. 35-59.

ARGENTE DEL CASTILlo OCAÑA, Carmen, «Últimos episodios de cautiverio fronterizo en la revuelta mudéjar, 1500-1501», $R L, 9 / 10$ (1988-1989), pp. 109-118.

ARIAS ABELLÁN, Jesús, «Los hombres y la tierra en los orígenes del señorío del Cenete. 1490-1568», FCL, 3-4, (1983), pp. 35-43.

ARMAda Morales, T. y Escayuela CuenCA, E., «La presencia castellana y su acción en Salobreña y su tierra (1489-1511). (Notas para su estudio)", CEM, X-XI (1983), pp. 93-104.

AsEnjo SEDANO, Carlos, «Trabajo, honra y esclavos en la Granada de los ss. XVI/XVII», RCHG, 6 (1992), 2a época, pp. 223-254. 
Barea Ferrer, José Luis, «La defensa de Motril en la época de los Austrias. Factor condicionante de su decadencia», CN, 17 (1989), pp. 9-24.

- «La población de la costa del Reino de Granada en 1567 a través de la visita de Antonio Moreno", CGUG, 14 (1984-84), pp. 147-175.

Barrios Aguilera, Manuel, «Ainadamar en el Archivo de la Facultad de Teología de Cartuja (Granada). Memoria de investigación histórica», RCHG, 7 (1993), $2^{2}$ época, pp. 307-355.

- «Paisajes agrarios moriscos en Granada (a través de los libros de Apeo)», RCHG, 3 (1989), $2^{a}$ época, pp. 217-237.

BENÍTEZ SÁnCHEZ-BlanCo, Rafael, "Control político y explotación económica de los moriscos: Régimen señorial y protección», CN, 20 (1992), pp. 9-26.

BIRRIEL SAlCEDO, Margarita $\mathbf{M}^{a}{ }^{2}$, «Notas sobre la hacienda municipal de Granada», CN, 10 (1979), pp. 123-139.

- «Nuevos datos sobre el patrimonio confiscado a los moriscos: La costa de Granada», CN, 21 (1993/1994), pp. 31-61.

- «Propiedad y uso de la tierra en los lugares de moriscos de la jurisdicción de Almuñécar (1550-1570)», MEAH, XXXVII (1988), fasc. 1', pp. 23-36.

- «Ventas de bienes confiscados a moriscos en la tierra de Almuñécar», $C N, 16$ (1988), pp. 39-54.

Bravo CARO, Juan Jesús, «Medidas adoptadas por el cabildo malagueño ante la sublevación morisca (1568-1570)», JB, 52 (1986), pp. 15-20.

— «Poblaciones moriscas de Málaga en el siglo XVI (1568-1571)», BT, 13 (1991), pp. 217-225.

CABANELAS, Darío, O.F.M., "Arias Montano y los libros plúmbeos de Granada», MEAH, XVIII-XIX (1969-1970), fasc. 1, pp. 7-41.

- «Cartas del morisco granadino Miguel de Luna», MEAH, XIV-XV (19651966), fasc. $1^{\circ}$, pp. 31-47.

— «Diego Marín, agente de Felipe II en Marruecos», MEAH, XXI (1972), fasc. 1, pp. 7-35.

— «Pedro Venegas de Córdoba, embajador de Felipe II en Marruecos», MEAH, XXII (1973), fasc. $1^{\circ}$, pp. 129-144.

CABrillanA, Nicolás, «Esclavos moriscos en la Almería del siglo XVI», $A A, \mathrm{XL}$ (1975), pp. 53-128.

— «La defensa costera del Reino de Granada: la iniciativa privada», CN, 17 (1989), pp. 25-32.

Calero Palacios, Carmen, «Contribución al estudio del espionaje morisco a través de un documento del Archivo de la Alhambra», CA, 14 (1978), pp. 147-150.

CAmpos Daroca, Ma. Luisa, «Rentas particulares del Reino de Granada tras la expulsión de los moriscos en 1570. La farda y la renta de población», CN, 16 (1988), pp. 55-66.

CARDAILLAC, Louis, «El enfrentamiento entre moriscos y cristianos», CN, 20 (1992), pp. 27-37.

— «Morisques et protestants», AA, XXXVI (1971), pp. 29-61. 
CARRASCO URGOITI, $\mathrm{M}^{\mathrm{a}}$. Soledad, «Experiencia y fabulación en las guerras civiles de Granada de Ginés Pérez de Hita», en MEAH, XLII-XLIII (1993/1994), pp. 49-72.

CASTILlo FERNÁNDEZ, Javier, "Arrendamientos de bienes confiscados a moriscos en Baza y su tierra (1571-1616)», CN, 21 (1993/1994), pp. 63-98.

CERro BeX, Victoriano del, «El repartimiento de Vera de 1496», $R L, 6$ (1985), pp. 3-33.

— «Un padrón de los mudéjares de la Tierra de Vera en 1495», CN, 11 (1980), 57-87.

— «Vera y su Tierra a comienzos del siglo XVI», RL, 5 (1984), pp. 147-163.

COTES PORCEL, Josefa, «La repoblación de tierras de los moriscos y su problemática según una referencia histórica: La visita que se realiza a la villa de Vélez Rubio en 1593», $R V, 4$ (1985), pp. 19-29.

Chavarría VARgas, Juan Antonio, «De la fortaleza y sierra de Bentomiz», JB, 46 (1984), pp. 11-26.

Díaz García, A. y Barrios AguILERA, M., «Nueva interpretación de viejos topónimos de Granada», MEAH, XXXIV-XXXV, fasc. $1^{\circ}$ (1985-1986), pp. 61-71.

DOMíNGUEZ BÉDMAR, Manuel, «Algunas posibles piezas de vajilla doméstica de época mudéjar y morisca», $R L, 9 / 10$ (1988-1989), pp. 101-108.

DOMÍNGUEZ ORTIZ, Antonio, "Los moriscos granadinos antes de su definitiva expulsión», MEAH, XII-XIII (1963-1964), fasc. $1^{\circ}$, pp. 113-128.

- «Notas para una sociología de los moriscos españoles», MEAH, XI (1962), fasc. $1^{\circ}$, pp. 39-54.

EPalzA, Míkel de, «Moriscos y andalusíes en Túnez durante el siglo XVII», $A A$, XXXIV (1969), pp. 247-327.

- «Sobre un posible autor español del Evangelio de Barnabé», AA, XXVIII (1963), pp. $479-491$.

ESPINAR MORENO, Manuel, «Abulcaçen Aben Cohbe se convierte al cristianismo como Diego de Mendoza. El Alguacilazgo de Purchena en manos de esta familia desde octubre del 1500 hasta 1568», RL, 7/8 (1986-1987), pp. 83-114.

— «Apeo y deslinde de los habices de Dílar (1547)», MEAH, XXIX-XXX (19801981), fasc. $1^{\circ}$, pp. 135-161.

- «Aproximación al conocimiento de la vida rural bastetana: notas sobre cultura material y mentalidades de los cristianos viejos y moriscos», MEAH, XXXVIII (1989-1990), fasc. $1^{\circ}$, pp. 53-68.

- «Aspectos urbanos y rurales de Cantoria musulmana y morisca», RL, 4 (1983), pp. 109-124.

— «Bienes habices de Churriana de la Vega (1505-1548)», CEM, VI-VII (19781979), pp. 55-78.

— «Escenas de la vida cotidiana de Purchena y su tierra en época musulmana y morisca (siglos XV y XVI)», RL, 9/10 (1988-1989), pp. 29-58.

— «Iglesias y ermitas de Baza en 1492. Dotación de los Reyes Católicos», CEM, 16 (1991), pp. 83-98.

- «La alquería de Otura. Datos para el estudio del Reino de Granada», AUC, I (1984), pp. 63-78. 
- «Los árboles en las tierras de Cantoria. Suertes confeccionadas y reparto», RL, 6 (1985), pp. 139-169.

- «Medidas de peso, capacidad y otras en las Alpujarras según los Libros de Habices», CGUG, 11 (1981), pp. 309-318.

- «Notas sobre la alquería de Cájar (1505-1547)», CEM, XIV-XV (1985-1987), pp. 47-60.

- «Notas sobre la historia de la villa de Cantoria. Bienes de la población morisca», $R L, 3$ (1982), pp. 81-95.

— «Notas sobre propiedades de algunas familias en Baza (1493-1520)», CEM, XII-XIII (1984), pp. 25-45.

- «Noticias para el estudio de la alquería de Gójar. Bienes habices», CEM, X-XI (1982-1983), pp. 105-148.

- «Reparto de las aguas del río Abrucena (1420-1533)», CN, 15 (1986-87), pp. 127-147.

Espinar Moreno, M. y Alvarez del Castillo, Mª.A., «Análisis socioeconómico de una alquería del valle del Almanzora en época musulmana y morisca: el caso de Sierro», $R L, 7 / 8$ (1986-1987), pp. 167-193.

Espinar Moreno, M., Alvarez del Castillo, $M^{a}$.A., y Guerrero Lafuente, $M^{a}$.D., «La alquería de Laroya. De la Edad Media a la Moderna. Notas para su estudio», RL, 9/10 (1988-1989), pp. 59-99.

Espinar Moreno, M. y Fernández Ortega, A., «Bienes rústicos de Cantoria. Suertes de Vega confeccionadas en tierras de regadío», $R L, 6$ (1085), pp. 93-137.

EsPinar Moreno, M. y García GuZMÁN, $\mathbf{M}^{a}$. del M., «Notas sobre la esclavitud de los moriscos albojences (siglo XVI)», RL, 2 (1981), pp. 49-69.

EsPINAR MORENo, M. y GRIMA CERvantes, J., «Un personaje almeriense en las crónicas musulmanas y cristianas. El infante Cidi Yahya Alnayar (1435?-1506): Su papel en la guerra de Granada», BIEA, 7 (1987), pp. 57-83.

ESPINAR MORENo, M. y QUESAda GómeZ, J.J., «Estudios sobre la ciudad de Baza en época musulmana y morisca. Los efectos del terremoto de 1531 en la estructura urbana», MEAH, XL-XLI (1991/1992), fasc. $1^{\circ}$, pp. 87-110.

- «Las aguas de la Acequia Alta o de Mecina (Cogollos de Guadix). Los pleitos desde los siglos XII al XVIII. Algunas notas para su estudio», MEAH, XLII-XLIII (1993-1994), fasc. $1^{\circ}$, pp. 81-95.

Espinar Moreno, M., Quesada Gómez, J.J. y Mª.D., «Las aguas del río Nacimiento

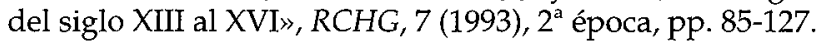

ESPINAR MORENO, M. y QUESADA GómeZ, Mª.D., «El regadío en el distrito del castillo de Sant Aflay repartimiento del río de la Ragua (1324-1524)», EHAM, V-VI (1985-1986), pp. 127-157.

Espinar Moreno, M., Quesada Gómez, J.J. y Sáez Medina, J., «La villa de La Peza. De lo musulmán a lo cristiano. 1: El ejemplo de la mezquita convertida en Iglesia y otros materiales», BIEP, 5 (1992), pp. 39-50.

Espinar Moreno, M. y Ruiz PÉrez, R., «Datos para el estudio de los judíos y mudéjares del Marquesado del Cenete», MEAH, XXXII (1983), fasc. 2, pp. 113-132. 
FRANCO SILVA, Alfonso, «Datos demográficos y organización municipal de las villas almerienses de los Vélez (1492-1540)», GD, 5 (1980), pp. 85-111.

— «El señorío de los Vélez entre 1492 y 1540. Población y Concejos», RV, 12 (1993), pp. 5-12.

GALÁN SÁNCHEZ, Angel, «Algunos rasgos de la propiedad mudéjar en la Ajarquía de Vélez-Málaga», BT, 11 (1988), pp. 353-365.

- Los moriscos de Málaga en la época de los Reyes Católicos, JB, 39 -monográfico(1982), pp. 1-80.

- «Notas para el estudio del origen de la cuestión morisca. Las bases socioeconómicas: el obispado de Málaga», HID, 9 (1982), pp. 273-326.

GALIANO PUY, Rafael, «Historia de los moriscos procedentes del reino de Granada, que se asentaron en las villas de Cambil y Alhabar», BIEG, 143 (enero-junio, 1991), pp. 39-56.

GARCÍA CÁRCEL, Ricardo, «La revuelta morisca de Espadán», AA, XLI (1976), pp. 121146.

García GuZMÁN, $\mathrm{M}^{\mathrm{a}}$. del Mar, «Bienes habices del convento de Santo Domingo de Almería (1496)», EHAM, II (1982), pp. 29-42.

GARCÍA LATORRE, Juan, «La pervivencia de los espacios agrarios y los sistemas hidráulicos de tradición andalusí tras la expulsión de los moriscos», RCHG, 6 (1992), pp. 297-317.

GarCía-AREnAl, Mercedes, «Dos documentos sobre los moros de Uclés en 1501», AA, XLII (1977), fasc. 1, pp. 167-181.

— «Las actas parroquiales de Comares (Málaga), 1564-1570», AA, XLII (1977), fasc. 2 , pp. 453-463.

- «Moriscos e indios. Para un estudio comparado de métodos de conquista y evangelización», CN, 20 (1992), pp. 153-175.

GARZÓN PAREJA, Manuel, «Cortijos del término de Granada que pertenecían a moriscos», CA, 13 (1977), pp. 63-83.

GARRIDO ARANDA, Antonio, «Papel de la Iglesia de Granada en la asimilación de la sociedad morisca», AHMC, 2-3 (1975-76), pp. 69-103.

GIL SANJUÁN, Joaquín, «Disidentes y marginados de la Serranía de Ronda en el tránsito a los tiempos modernos», BT, 13 (1991), pp. 227-239.

- «El parecer de Galíndez de Carvajal sobre los moriscos andaluces (año 1526)», BT, 11 (1988), pp. 385-401.

— «La Inquisición de Granada: Visita a Málaga y su comarca en 1568», BT, 1 (1978), pp. 313-336.

— «La otra cara de la Inquisición», JB, 29 (1980), pp. 66-77.

— «Moriscos, turcos y monfíes en Andalucía mediterránea», BT, 2 (II) (1979), pp. 133-167.

- «Ofensiva final antimorisca de la Inquisición granadina», BT, 12 (1989), pp. 187-196.

— «Presión material sobre los moriscos andaluces», BT, 3 (1980), pp. 185-206. 
GLICK, Thomas F., «Historia del regadío y las técnicas hidráulicas en la España medieval y moderna. Bibliografía comentada», CN, I, 18 (1990), pp. 191-122; II, 19 (1991), pp. 167-192; Addenda, 20 (1992), pp. 209-232.

GÓmEZ LORENTE, M., «Aportaciones al estudio del marquesado del Cenete», CEM, XII-XIII (1984), pp. 85-93.

- «Los Señoríos en el Reino de Granada. El Señorío de Gor», CEM, XIV-XV (1985-1987), pp. 61-74.

GOZALBES BUSTO, Guillermo, "Cautiverios y redenciones en el Marruecos de la Edad Moderna. El caso de Cuevas de Almanzora», RCHG, 4 (1990), pp. 213-229.

— «Huellas vejeriegas en el Norte de Marruecos», EHAM, II (1982), pp. 61-70.

- «La nobleza granadina en la fundación y desarrollo de Tetuán (siglos XV al XVII)», MEAH, XL-XLI (1991-1992), fasc. 1ํ. pp. 141-159.

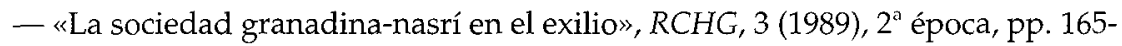
181.

— «Notas sobre la tradición oral morisca en Tetuán», ACUA, II, año IV (1982), pp. 101-104.

— «Personajes moriscos en el Tetuán del siglo XVII», RCHG, 5 (1991), pp. 155-170.

GozAlBes CRAVIOTO, Carlos, «Andalucía y el contrabando de armas en Marruecos en el siglo XVI», $A H, 192$ (1980), pp. 177-189.

Grima CervanTES, Juan Antonio, «Gobierno y administración de Granada tras la conquista: las ordenanzas de la Alhambra de 1492», CA, 26 (1990), pp. 169-179.

- «Las capitulaciones pactadas en 1488 y en 1501 entre los Reyes Católicos y los Mudéjares de Vélez Blanco y Vélez Rubio», RV, 6 (1987), pp. 75-85.

Gual Camarena, M. y López de Coca Castañer, J.E., «La sal del reino de Granada. Documentos para su estudio", CEM, II-III (1974-1975), pp. 259-296.

HARveY, L.P., «A morisco Manuscript in the Godolphin Collection at Wadham College, Oxford», AA, XXVII (1962), pp. 461-465.

- «A morisco prayer-book in the British Museum», AA, XXIX (1964), pp. 373-376.

- «A morisco reader of Jean Lemaire de Belges?», $A A$, XXVIII (1963), pp. 231-236.

— «The Arabic Dialect of Valencia in 1595», AA, XXXVI (1971), pp. 81-117.

JIMÉNEZ JURADO, $\mathrm{M}^{\mathrm{a}}$. Isabel, «La encomienda infantil: una modalidad de dependencia personal en la Almería del s. XVI», IX C.P.I., Málaga, 1991, pp. 173-178.

LABARTA, Ana, «Textos para el estudio de terapéutica entre los moriscos valencianos», DY, 1 (1981), pp. 275-310.

LABARTA, A. y BARCELó, C., «Nuevas recetas médicas de moriscos valencianos», $D Y$, 7-8 (1987-88), pp. 347-354.

López, Angel C., «El alcorán morisco de la Biblioteca de las Escuelas Pías de Granada», RCHG, 2 a época, 2 (1988), pp. 59-63.

LÓPEZ, Miguel, «El Colegio de los niños moriscos de Granada (1526-1576)», MEAH, XXV (1976), pp. 33-68.

LÓPEZ ANDRÉS, Jesús $M^{\mathrm{a}}$., «Real Patronato Eclesiástico: la Iglesia de Almería, como Iglesia de Estado la época de los Reyes Católicos», BIEA, 1 (1981), pp. 141-145. 
LóPEZ BELTRÁN, María Teresa, "Un impuesto sobre la exportación de frutos secos en el reino de Granada: el mucharan», MEAH, XXXII-XXXIII (1983-1984), fasc. $1^{\circ}$, pp. 95-110.

LóPEZ DAPENA, $M^{\mathrm{a}}$. Asunción, «Las rentas de Guadix de 1494, 1501 y 1502», CEM, XXI (1982-1983), pp. 149-167.

LÓPEz RuIz, Emilio, «La guerra contra los moriscos vista desde Jaén», BIEG, 60 (1969), pp. 9-97.

LÓPEZ DE COCA CASTAÑER, José-Enrique, «Financiación mudéjar del sistema de la vigilancia costera en el Reino de Granada (1492-1501)», HID, 3 (1976), pp. 397-415. (Reed. en su vol. misceláneo El Reino de Granada en la época de los Reyes Católicos: Repoblación, comercio y frontera. II, Granada, Universidad, 1989, pp. 183-203).

— «Fuengirola, un caso de repoblación fallida», JB, 9 (1975), pp. 13-16.

— «La "conversión general" en el obispado de Málaga (1500-1501)», CN, 21 (1993/1994), pp. 191-237.

- «Poblamiento y frontera en el obispado de Málaga a fines del siglo XV. Introducción a su estudio», CEM, II-III (1974-1975), pp. 367-407. (Reed. en El Reino de Granada... I, pp. 13-58).

— «Privilegios fiscales y repoblación en el reino de Granada», BT, 1 (1978), pp. 205-223. (Reed. en El Reino de Granada... I, pp. 171-203).

- «Relaciones mercantiles entre Granada y Berbería en época de los Reyes Católicos», BT, 1 (1978), pp. 293-311. (Reed. en El Reino de Granada... II, pp. 57-66).

LuNA DíAZ, Juan Andrés, «Apuntes para el estudio de la agricultura de Granada y su tierra en los primeros años de la conquista», $C N, 10$ (1979), pp. 231-248.

— «El Temple, Tierra de Granada, en el siglo XVI», CN, 15 (1986 1987), pp. 227-254.

- «La alquería: un modelo socio-económico en la Vega de Granada. Aproximación a su estudio», CN, 16 (1988), pp. 79-100.

- «La parroquia de Santa María Magdalena de Granada, un barro en expansión hacia la Vega durante el siglo XVI», CN, 11 (1980), pp. 187-244.

- «Repoblación y gran propiedad en la región de los Montes de Granada durante el siglo XVI. El cortijo", CN, 17 (1989), pp. 171-204.

Lladó GRANADO, A.I. y AlCAINA FERNÁNDEZ. P., «Visita inquisitorial al Obispado de Almería -Año 1561-», BIEA, 9/10 (1991), pp. 43-79.

MalPiCA CUEllo, Antonio, «La costa de Granada a fines de la Edad Media», VII C.P.I., Córdoba, 1989 , pp. 11-26.

- «La implantación castellana en la tierra de Salobreña: la alquería de Benardila», $R C H G, 3$ (1989), $2^{a}$ época, pp. 199-216.

- «La villa de Motril y la repoblación de la costa de Granada (1489-1510)», CEM, X-XI (1982-1983), pp. 169-206.

— «Las salinas de Motril. (Aportación al estudio de la economía salinera del reino de Granada a raíz de su conquista)», BT, 4 (1981), pp. 147-165.

- «Primeros elementos de análisis de la estructura de poblamiento de Almuñécar y su alfoz a fines de la Edad Media», $A A H$, II (1983), pp. 375-399. 
Malpica Cuello, A. y Rodríguez Lozano, J.A., «La alquería de Cázulas y la tierra de Almuñécar a finales del siglo XV (Notas y documentos para su estudio)», EHAM, II (1982), pp. 71-89.

Malpica Cuello, A. y TRILlo SAN José, C., «Los Infantes de Granada. Documentos árabes romanceados», $R C H G, 6$ (1992), $2^{\text {a }}$ época, pp. 361-421.

MARTín RuIZ, F., «La economía del partido de Marbella en los años anteriores al levantamiento de los moriscos en 1568», CCEE, 13 (1984), pp. 63-78.

MARTín RuIz, José María, «Distribución de los bienes moriscos de un pueblo de la Axarquía en el último tercio del siglo XVI (Cómpeta)», JB, 44 (1983), pp. 21-26.

- «Los lugares de señorío del partido de Bentomiz en el último tercio del siglo $\mathrm{XVI} \gg, B T, 10$ (1987), pp. 273-280.

Martínez López, J.M., Fuente ARIAs, J. de la, y Granados Romero, P., «Estudio de dos despoblados de la sierra de los Filabres: Alhabia y Benimina», BIEA, 3 (1983), pp. 39-58.

MARTínez Ruiz, Juan, «Antroponimia morisca en Cantoria (año 1572)», RL, 4 (1983), pp. 81-108.

- «Ausencia de literatura aljamiada y conservación del hispano-árabe y de la entidad árabo-musulmana en la Granada morisca (siglo XVI)», CN, 21 (1993/1994), pp. 405-425.

— «El Ár. 'Ard 'Tierra', y el Ár. Granadino Qatra 'Haza', en la toponimia menor Granadina (siglo XVI)», EHAM, V-VI (1985-1986), pp. 301-318.

— «Hufra, hayar y sajar en el manuscrito inédito de Habices de 1527», MEAH, XXIX-XXX (1980-81), fasc. $1^{\circ}$, pp. 107-119.

- «La indumentaria de los moriscos, según Pérez de Hita y los documentos de la Alhambra», CA, 3 (1967), pp. 55-124.

- «Recibos bilingües de pago de farda en el Archivo de la Alhambra (Año 1563)», RCHG, 1 (1987), $2^{\mathrm{a}}$ época, pp. 271-291.

— «Visita a todas las casas del Albaicín en el año 1569 (Antroponimia, etnología y lingüística)», CA, 15-17 (1979-1981), pp. 255-298.

- «Visita a todas las casas del Albaicín en el año 1569 (Antroponimia, etnología y lingüística). II», CA, 18 (1982), pp. 239-273.

- «Visita a todas las casas del Albaicín en el año 1569. III. San Gregorio, San Luis, San Nicolás. (Antroponimia, etnología y lingüística)», CA, 19-20 (19831984), pp. 247-283.

Martínez Ruiz, J. y Barrios Aguilera, M., «Contribución a la toponimia andaluza: Loja y su tierra. Historia y lingüística (según el Libro de Repartimiento, 14861506)», FCL, 7-8 (1984), pp. 26-56.

MOLINA MOLINA, Angel Luis, «Moriscos murcianos procedentes del valle del Almanzora según el registro de 1573», RL, 2 (1981), pp. 71-77.

MONROE, James T., "A curious morisco appeal to the Ottoman Empire», $A A, \mathrm{XXXI}$ (1966), pp. 281-303.

Moreno Olmedo, $\mathrm{M}^{\mathrm{a}}$. Angustias, «Contribución al estudio de la cuenca del Almanzora (Albox-Farda)», RL, 2 (1981), pp. 35-41. 
MuÑoz BuENDíA, Antonio, «Supervivencia de la población morisca en Almería después de la expulsión de 1570: ejemplo de algunas familias» IX C.P.I., Málaga, 1991, pp. 503-525.

MuÑoz MARTíN, Ma . del M. y DOMÍNGUez BÉDMAR, M., «Cerámica hispanomusulmana del Cerro del Castillo (Albox, Almería)», $R L, 5$ (1985), pp. 3-46.

NAVAS ACOSTA, Antonio, «La batalla de Frigiliana o la rebelión de Bentomiz», JB, 9 (1975), pp. 17-26.

NúÑ̃z CONTRERAS, Luis, «La fecha de consagración de las mezquitas y la erección de la Colegiata del Albaicín de Granada», HID, 6 (1979), pp. 219-247.

NúNez Galiano, Pilar, «La comarca de Bentomiz en sus fuentes documentales», JB, 48 (1984), pp. 9-14.

Peinado SANTAella, Rafael G., «Los Banu al-Qabvani: Un linaje de la aristocracia nazarís, en HID, 20 (1993), pp. 313-353.

- «Los orígenes del Marquesado de Campotéjar (1514-1632): Una contribución al estudio de los señoríos del Reino de Granada», CN, 17 (1989), pp. 261-279.

Pereiro Barbero, Presentación, «Incidencia de la expulsión de los moriscos de la Axarquía. Aspectos demográficos y urbanísticos», BT, 11 (1988), pp. 403-416.

Pérez García, J., «El poblamiento de la taha de Suhail a fines de la Edad Media: el castillo de Castell de Ferro», CEM, XII-XIII (1984-1985), pp. 139-153.

PÉrez de Colosía Rodríguez, Ma. Isabel, «Malagueños sentenciados por el Santo Oficio de Granada en 1550», BT, 10 (1987), pp. 293-307.

- «Represión inquisitorial después de la guerra de las Alpujarras», BT, 12 (1989), pp. 217-238.

— «Visita inquisitorial de 1560 por tierras malagueñas», BT, 9 (1986), pp. 331-345.

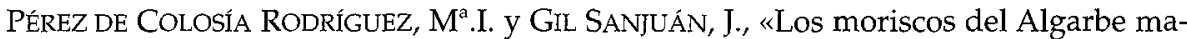
lagueño: Orígenes y presión inquisitorial», $J B, 56$ (1987), pp. 13-27.

- Málaga y la Inquisión, JB, 38 -monográfico- (1982), pp. 1-100.

PINO, Enrique del, «La esclavitud en Málaga», JB, 14 (1976), pp. 3-68.

PORRAS ARBOLEDAS, Pedro A., «Documentos sobre musulmanes y judíos en archivos señoriales y de protocolos (siglos XV y XVI)», CEM, XVI (1991), pp. 127-157.

Puga Barroso, José Luis, «Moriscos de la Tahá de Orgiva huidos a Berbería», XI C.P.I., Córdoba, 1994, pp. 111-118.

RODRÍGUEZ MARTíNEZ, Francisco, "Aspectos socioeconómicos de la repoblación de Almería por los Reyes Católicos», CGUG, 2 (1972), pp. 41-52.

RODRÍGuez MOLINA, Faustino, «Los conocedores moriscos y cristianos viejos en la repoblación de la Alpujarra de Granada», IX C.P.I., Málaga, 1991, pp. 527-547.

RODRíGuez MOLINA, José, "Participación de Jaén en el sometimiento de los mudéjares rebeldes de Almería», $R L, 9 / 10$ (1988-1989), pp. 119-128.

RuIz PÉrez, Ricardo, "El levantamiento morisco en tierras de señorío. El caso del marquesado del Cenete», CN, 19 (1991), pp. 291-336.

- «El magrán, impuesto decisivo en la progresiva señorialización del Marquesado del Cenete durante la época morisca», CN, 14 (1986), pp. 293-328. 
RUIZ VERA, J.L., "El mundo rural ante la Inquisición», VIII C.P.I., Córdoba, 1990, pp. 337-369.

SÁez MediNA, Juan, «El Santo Fray Marcos Criado, apóstol de los moriscos», BIEP, 5 (1992), pp. 55-59.

— «Tres informaciones sobre la parroquia de La Peza en el siglo XVI», BIEP, II-2 (1989), pp. 63-72.

SÁNCHEZ RAMOS, Valeriano, «Agua y regadío en la Alpujarra Almeriense (siglos XVI y XVII)»CN, 19 (1991), pp. 337-382.

SANTIAGO SIMÓN, Emilio de, «Algunos datos sobre la posesión de los bienes raíces moriscos en el lugar de Cenes de la Vega de Granada (1572)», MEAH, XXII (1973), fasc. $1^{\circ}$, pp. 153-161.

- «Algunos documentos arábigo-granadinos romanceados del Archivo

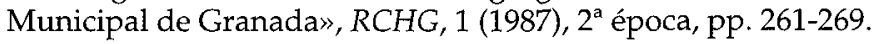

SANZ SAMPELAYO, Juan, «Configuración inicial e instauración del Cabildo de Granada. Estado de la cuestión y nuevas notas», BT, 7 (1984), pp. 303-310.

SECO DE LuCENA PAREDES, Luis, «Toponimia árabe de la vega y montes de Granada», $A A$, XXIX (1964), pp. 311-327.

SORIA MESA, Enrique, «Don Alonso de Granada Venegas y la rebelión de los moriscos. Correspondencia y mercedes de don Juan de Austria», CN, 21 (1993/1994), pp. 547-560.

- «La venta de bienes de la casa real. El caso de Gor bajo Muhammad El Izquierdo», en MEAH, XLII-XLIII (1993/1994), pp. 291-304.

Suberbiola Martínez, Jesús, «Constituciones y rentas decimales del obispado de Málaga», CEM, XII-XIII (1984), pp. 205-232.

- «Fisco, franquicias y problemas en la repoblación de Málaga (siglos XVXVI)», CEM, II-III (1974-1975), pp. 149-196.

— «La erección parroquial Granantense de 1501 y el reformismo Cisneriano», CEM, XIV-XV (1985-1986), pp. 115-144.

— «La ordenación parroquial malacitana de 1505 y su reformación», BT, 8 (1985), pp. 311-354.

— «Política fiscal en la conversión general mudéjar», BT, 2 (I) (1978), pp. 251-263.

SZMOLKA CLARES, José, «La reactivación de la economía granadina a raíz de la conquista castellana», AHMC, 4-5 (1977-1978), pp. 127-149.

TAPia Garkido, José Angel, «Don Juan de Austria en el Almanzora», RL, $7 / 8$ (19861987), pp. 145-165.

— «El cura de Albox, cautivo en Argel», RL, 2 (1981), pp. 43-48.

— «El señorío de los Fajardo en el Almanzora», RL, 1 (1980), pp. 109-125.

— «El último Abduladin», RV, 5 (1986), pp. 41-45.

— «Expulsión de los moriscos de los Vélez», $R V, 8$ (1989), pp. 5-14.

- «La agricultura en el Almanzora durante la Baja Edad Media», RL, 3 (1982), pp. 23-33.

— «Los señoríos del Almanzora», $R L, 4$ (1983), pp. 55-62. 
— «Primera iglesia y primeros cristianos de Vélez Rubio», RV, 2 (1983), pp. 35-54.

— «Rebelión de los moriscos del Almanzora», $R L, 6$ (1985), pp. 35-55.

TORRES, José Carlos de, «Brujas, pícaros y celestinas de Andújar en la literatura española del Siglo de Oro", BIEG, 127 (1986), pp. 77-89.

TORRES PAlOMO, $\mathrm{M}^{\mathrm{a}}$. Paz, "Sobre la carta de Abenaboo en árabe granadino", $M E A H$, XVIII-XIX (1969-1970), fasc. $1^{\circ}$, pp. 125-128.

VALLVÉ BERMEJO, Joaquín, «Sobre el repartimiento de Comares (Málaga)», AA, XXXIX (1974), pp. 257-272.

VÁZQUEZ QUERO, Ascensión, «A propósito de la cultura material en el reino de Granada: Elementos de ajuares domésticos según la notaría de García de Castilla (1528)», CEM, XII-XIII (1984), pp. 233-244.

Vera Delgado, Ana $M^{\mathrm{a}}$., "La readaptación del sistema de defensa costera en el Obispado de Málaga (1501-1511)», BT, 4 (1981), pp. 193-208.

VILAR, Juan Bautista, «Los moriscos de la gobermación y obispado de Orihuela», $A A$, XLIII (1978), pp. 323-367.

VILLEGAS MOLINA, Francisco, «Algunas consideraciones sobre la expulsión de los moriscos del Reino de Granada en el siglo XVI», CGUG, 8 (1978), pp. 271-283.

VINCENT, Bernard, «La famille Morisque», HID, 5 (1978), pp. 469-483. Versión en castellano en su vol. misceláneo Minorías y marginados en la España del siglo XVI, Granada, Diputación Provincial, 1987, pp. 7-24.

— «La vision du Royaume de Grenade pour les voyageurs étrangers au tournant des XVème et XVlème siècles», $C N, 15$ (1986-1987), pp. 301-312.

- «Le réseau d'irrigation du royaume de Grenade au XVIe siècle», HG, 2 (1988), $2^{\mathrm{a}}$ época, pp. 65-76.

— «Los moriscos y la Inquisición (1563-1571)», CN, 13 (1982-83), pp. 197-206.

WAGNER, Klaus, «Un padrón desconocido de los mudéjares de Sevilla y la expulsión de 1502», $A A$, XXXVI (1971), pp. 373-382. 